\title{
Algumas considerações em torno da expressão da posterioridade no passado, no contexto de completivas de verbo
}

\section{Some remarks about the expression of posteriority in the past in the context of verbal complement clauses}

\author{
Luís Filipe Cunha \\ Centro de Linguística da Universidade do Porto, Faculdade de Letras \\ Universidade do Porto, Porto / Portugal \\ luisfilipeleitecunha@gmail.com
}

Resumo: A expressão da posterioridade num domínio passado pode ser alcançada, em Português Europeu, por meio do recurso a diferentes tempos gramaticais, destacando-se o Imperfeito Simples do Indicativo, o Condicional e a estrutura ir no Imperfeito + Infinitivo. O presente trabalho procura evidenciar as diferenças interpretativas decorrentes da utilização de cada uma dessas formas verbais. Tendo em vista o objetivo aqui delineado, e após uma breve caracterização semântica de cada uma delas, o artigo explora as suas possibilidades interpretativas no contexto de quatro tipos de completivas de verbo, a saber: verbos declarativos, como dizer ou afirmar; verbos orientados para o futuro, como prometer ou decidir; verbos factivos, como constatar ou descobrir, e verbos que favorecem leituras modais de cariz intensional do gênero de acreditar, sonhar ou imaginar. Concluiremos que as interpretações futurativas derivam de um conjunto de elementos linguísticos em interação dinâmica, que em muito ultrapassam o simples papel dos tempos gramaticais, já que envolvem fatores como as propriedades lexicais do verbo matriz, a presença de certos adverbiais temporais ou o perfil aspectual das situações representadas. 
Palavras-chave: semântica; tempos gramaticais; posterioridade no passado; orações completivas de verbo.

Abstract: In languages such as European Portuguese, the expression of a posteriority relation within a past domain can be achieved through the use of different tenses, the most relevant being the Imperfeito do Indicativo (Imperfect), the Condicional (a tense that somehow corresponds to would + Infinitive) and the structure ir ('go') in the Imperfect + Infinitive. The paper aims to shed some light on the interpretative differences corresponding to the selection of each of these verbal forms. With this purpose in mind, and after a brief semantic characterisation of the three tenses under discussion, the article explores their interpretative possibilities arising in the context of four kinds of complement clauses, namely those headed by saying verbs like dizer ('to say') and afirmar ('to claim'); by future-oriented verbs such as prometer ('to promise') or decidir ('to decide'); by factive verbs like constatar ('to find') or descobrir ('to find out') and by verbs that favour an intensional modal reading like acreditar ('to believe'), sonhar ('to dream') or imaginar ('to imagine'). I conclude that the future-in-the-past readings typically derive from several linguistic factors interacting dynamically. Beside the central role played by tenses, the final interpretation of these constructions depends on a complex computation of grammatical features such as the lexical properties of the verb in the matrix clause, the presence or absence of certain temporal adverbials or the aspectual profile of the situations involved.

Keywords: semantics; tense; posteriority in past domains; verbal complement clauses.

Recebido em 4 de julho de 2017.

Aceito em 4 de setembro de 2017.

\section{Introdução}

A expressão da posterioridade em relação a um dado tempo passado pode ser obtida, em línguas como o Português Europeu (doravante PE), por meio de diferentes mecanismos linguísticos. Em 
particular, são várias as formas verbais que licenciam uma leitura desse gênero, como os seguintes exemplos parecem demonstrar:

(1) O João decidiu que comprava um carro novo.

(2) O João decidiu que compraria um carro novo.

(3) O João decidiu que ia comprar um carro novo.

Nas frases de (1) a (3), a situação representada na oração subordinada é interpretada como posterior em relação ao intervalo disponibilizado pela principal, independentemente de surgir o Imperfeito do Indicativo (cf. (1)), o Condicional (por vezes também designado como Futuro do Pretérito (veja-se, por exemplo, CUNHA; CINTRA, 1984; Peres, 1993; (cf. (2)) ou a construção ir no Imperfeito + Infinitivo (cf. (3)). Por outras palavras, a compra do carro novo pelo João é interpretada como sendo posterior ao intervalo de tempo em que ele toma a sua decisão. ${ }^{1}$

Significará essa proximidade, em termos interpretativos, que os três tempos gramaticais ${ }^{2}$ aqui representados são semanticamente idênticos?

A resposta a essa questão deverá ser, naturalmente, negativa, uma vez que, como tem sido frequentemente observado na literatura, cada uma dessas formas exibe propriedades semânticas e comportamentos linguísticos bastante distintos.

Como explicar, então, que tempos gramaticais tão diferentes entre si revelem a capacidade de exprimir futuridade em relação a um tempo passado?

No sentido de encontrar uma resposta tão satisfatória quanto possível para essa questão, é nosso objetivo, no presente trabalho,

\footnotetext{
${ }^{1}$ Sublinhe-se que nem todos os tempos gramaticais do PE permitem uma tal interpretação. Por exemplo, o Pretérito Perfeito resulta anômalo numa frase deste gênero na medida em que não se revela capaz de veicular uma leitura de futuro do passado, como (i) deixa bem claro.

(i) * O João decidiu que comprou um carro novo.

${ }^{2}$ Ao longo deste nosso trabalho, utilizaremos o termo "tempos gramaticais" como o equivalente, em português, à palavra inglesa tense. Para evitar ambiguidades e seguindo a sugestão de um revisor anônimo, a quem agradecemos, preferiremos a expressão "formas verbais", quando estão em causa relações estritamente anafóricas.
} 
averiguar os diversos contextos em que o Imperfeito Simples, o Condicional e a estrutura ir no Imperfeito + Infinitivo veiculam posterioridade em relação a um dado intervalo passado, procurando aferir em que medida as propriedades semânticas que possibilitam identificar cada uma dessas formas verbais nos ajudam a compreender as suas (im)possibilidades combinatórias. Para isso, começaremos por fornecer uma breve descrição do comportamento típico desses três tempos gramaticais, passando, em seguida, à verificação e à comparação sistemática das condições em que as interpretações de tipo futurativo são viabilizadas. Finalmente, tentaremos propor uma correspondência entre as propriedades semânticas que caracterizam cada um desses tempos gramaticais e as restrições que exibem no que se refere à capacidade de exprimirem futuridade em domínios temporais passados no contexto de diferentes tipos de completivas de verbo. Como veremos, a interação com outros elementos linguísticos como as propriedades lexicais do verbo matriz, a presença ou ausência de adverbiais temporais ou o perfil aspectual das situações envolvidas vão ser cruciais para a computação da interpretação final das estruturas sob análise.

\section{Breve caracterização semântica de alguns tempos gramaticais do PE}

Para melhor compreendermos as semelhanças e as diferenças que se podem observar entre o Imperfeito Simples, o Condicional e a estrutura ir no Imperfeito + Infinitivo, no que diz respeito à expressão da futuridade em contextos do passado, importa, antes de mais, proceder a uma análise, ainda que breve, das principais propriedades semânticas que possibilitam identificar cada uma dessas formas verbais, com particular ênfase na sua caracterização temporal, mas sem esquecer os eventuais efeitos aspectuais e modais que a elas estejam associados.

Nessa medida, recorreremos essencialmente às propostas de análise temporal desenvolvidas por Kamp e Reyle (1993) e por Declerck (1991, 2006).

Da abordagem temporal adotada por Kamp e Reyle (1993), na sua Teoria das Representações Discursivas (DRT), importa sobretudo destacar a noção de Ponto de Perspectiva Temporal (PPT), que corresponde à relação que se estabelece entre uma dada situação e o intervalo de tempo a partir do qual esta é "vista" ou "perspectivada". 
Sob um certo ponto de vista, podemos afirmar que o PPT se constitui como um intervalo de tempo que possibilita articular, de uma forma mais precisa e complexa, a relação entre o tempo do discurso (que pode ou não coincidir com o tempo da fala ou "speech time") e o tempo em que decorre a situação ("situation time"). Assim, o PPT pode ser [+Passado], se se localiza num intervalo anterior ao momento da enunciação, ou [-Passado], caso se verifique a coincidência entre o intervalo do PPT e o momento da enunciação. Por outro lado, o intervalo em que decorre a situação pode ser anterior, sobreposto ou posterior ao respectivo PPT. ${ }^{3}$ Nesse sentido, o recurso ao PPT é capaz de dar conta de relações de anterioridade, de sobreposição ou de posterioridade, não apenas em relação a um intervalo coincidente com o momento da fala, mas também a intervalos que se localizam no domínio do passado.

Uma abordagem desse gênero possibilita-nos dar conta de relações temporais que manifestem uma certa "sofisticação", nomeadamente no que concerne às interdependências que se estabelecem no interior de frases complexas. Possibilita, por exemplo, descrever adequadamente as várias relações temporais representadas numa configuração como a de (4):

(4) A Maria disse que ia estudar na biblioteca.

Em (4), a situação da oração principal, "A Maria dizer”, é localizada num intervalo anterior ao respectivo PPT, que, nesse caso, é coincidente com o momento da enunciação (i.e. TS $<$ PPT; PPT = TE). ${ }^{4}$ Já a situação representada na subordinada, "A Maria estudar na biblioteca", toma como Ponto de Perspectiva Temporal a eventualidade descrita na frase matriz, o que significa, em última instância, que o seu PPT é passado em relação ao momento da enunciação. Por outro lado, verificamos que

\footnotetext{
${ }^{3}$ Dado que o objeto de análise da DRT é o discurso como um todo, e não apenas frases isoladas, Kamp e Reyle (1993) reconhecem a necessidade de distinguir o seu Ponto de Perspectiva Temporal do Ponto de Referência, que, nesta abordagem, é sobretudo utilizado para possibilitar o encadeamento de situações na progressão narrativa. Sob esse ponto de vista, o PPT de Kamp e Reyle exibe pontos de contato importantes com a noção de Reference Time, tal como definida em Reichenbach (1947), embora, como veremos, a ideia de perspectiva temporal se afigure mais adequada para dar conta de relações temporais que envolvam um maior grau de complexidade.

${ }^{4}$ Em que TS corresponde a Tempo da Situação; PPT a Ponto de Perspectiva Temporal e TE a Tempo da Enunciação ou Tempo de Fala.
} 
a situação na subordinada é interpretada como decorrendo num intervalo que sucede ao PPT selecionado, obtendo-se, assim, uma relação de posterioridade no passado (i.e. TS $>$ PPT; PPT $<$ TE).

Das propostas de Declerck $(1991,2006)$ a que recorreremos ao longo do presente trabalho importa destacar a distinção que o autor sugere, no domínio temporal, entre a esfera do não-passado (ou do presente) e a esfera do passado. A esfera temporal não passada (ou presente) referese a um período indefinido de tempo que inclui necessariamente T0, o momento da enunciação. ${ }^{5}$ Já a esfera temporal do passado abarca um período indefinido de tempo que antecede inteiramente T0 sem o incluir. As esferas temporais dão conta do designado tempo absoluto, no sentido em que estabelecem uma relação direta (deítica) com o momento da enunciação.

Sempre que uma dada situação é localizada no interior de cada uma das esferas temporais, o TS (Tempo da Situação) estabelece uma localização relativa de anterioridade, de sobreposição ou de posterioridade em relação ao tempo absoluto em que se insere. Assim, numa frase como (4), a situação da matriz poderia ser caracterizada como anterior a Presente, ao passo que a situação da subordinada, dado que se inscreve na esfera do passado, seria descrita como posterior a Passado.

Com essas definições em mente, passemos, agora, à análise dos três tempos gramaticais que, em PE, possibilitam leituras de posterioridade no passado, a saber, o Imperfeito Simples, o Condicional e a estrutura ir com Imperfeito + Infinitivo.

\subsection{O Imperfeito Simples}

Em termos gerais, o Imperfeito pode ser caracterizado como um tempo passado que apresenta uma dada eventualidade ${ }^{6}$ como estando em progressão, i.e., sem fazer qualquer referência aos seus momentos inicial e final (cf. OLIVEIRA, 1987; DELFITTO; BERTINETTO, 1985; SMITH, 1991; GIORGI; PIANESI, 1997; FERREIRA, 2004; ANAND;

\footnotetext{
${ }^{5}$ Declerck propõe a existência de três setores que dividem a esfera do presente: o pré-presente, o presente e o pós-presente. Dado que não iremos recorrer a essa divisão ao longo do nosso trabalho, optamos por não discutir aqui os pormenores da sua caracterização.

${ }^{6} \mathrm{Na}$ esteira de Bach (1986), utilizaremos aqui o termo eventualidade com o significado de situação ou de estado de coisas.
} 
ACQUARD, 2009, entre outros). Como tal, o Imperfeito representa a situação com que se combina como homogênea e não terminada.

Por outro lado, o Imperfeito é tendencialmente uma forma verbal anafórica (ou relativa, na terminologia de DECLERCK, 1991, 2006) na medida em que requer a presença de um outro intervalo que não o momento da enunciação para ser adequadamente interpretado. Assim, o Imperfeito toma como seu PPT um dado tempo passado com o qual estabelece uma relação de sobreposição (cf. BERTHONNEAU; KLEIBER, 1993; MATOS, 1996; GIORGI; PIANESI, 1997). Esse intervalo pode ser fornecido por um adverbial temporal explícito, por orações temporais, pelo verbo principal de uma estrutura de complementação ou recuperado por meio de indicações contextuais. Sob esse ponto de vista, diversos autores consideram o Imperfeito como exprimindo um "presente do passado” (cf. e.g. PERES, 1993; GIORGI; PIANESI, 1997).

Tomando em linha de conta esse tipo de caracterização, Kamp e Rohrer (1983) defendem a ideia de que o Imperfeito se comporta como as predicações estativas, na medida em que, tal como elas, não introduz um novo Tempo de Referência no discurso, limitando-se a selecionar um dado intervalo preexistente com o qual estabelece uma relação de sobreposição. ${ }^{7}$

Por conseguinte, parece lícito concluir que o Imperfeito, para além do seu valor estritamente temporal de sobreposição a passado, comporta frequentemente importantes consequências ao nível aspectual. A confirmar essa hipótese, podemos invocar o fato de que, quando combinado com eventos, o Imperfeito atribui, por vezes, propriedades típicas de estatividade às predicações com que se combina. ${ }^{8}$

\footnotetext{
${ }^{7}$ Uma conclusão semelhante é avançada em de Swart (1998), que considera que o Imperfeito é um tempo gramatical que apenas se revela compatível com situações homogêneas, i.e., com estados e processos, ocasionando mudanças aspectuais quando se combina com outros tipos de eventualidades.

${ }^{8}$ Embora uma análise detalhada das propriedades de estatividade associadas ao Imperfeito esteja fora do âmbito do presente trabalho, discutiremos aqui, a título ilustrativo, um exemplo que vai ao encontro dessa linha de análise. Tendencialmente, no contexto de orações subordinadas introduzidas por quando, os estados estabelecem uma relação de inclusão com os eventos da principal com que coocorrem, mesmo se o tempo gramatical selecionado for o Pretérito Perfeito (cf. a leitura preferencial de uma frase como "Quando esteve em Paris, a Maria jantou num restaurante famoso" é aquela em que o evento de "jantar num restaurante famoso" se encontra incluído no
} 
Assim, é possível observar que, em contextos apropriados, o tempo gramatical em questão propicia alterações aspectuais significativas quando se combina com eventos. Em particular, favorece leituras de tipo habitual (cf. (5)) ou semiprogressivo (cf. (6)) para as predicações eventivas no seu escopo (cf. CUNHA, 2004/2007).

(5) Quando entrei na sala, o João tocava (= estava a tocar) piano. (leitura semiprogressiva)

(6) O João tocava piano no bar dos artistas (todos os sábados). (leitura habitual)

Comutações aspectuais desse gênero parecem ser essenciais para que a leitura continuativa de sobreposição a um dado intervalo passado, típica do Imperfeito, possa ser preservada. Como observado em Moens (1987) e Cunha (1998), para o Progressivo, e em Chierchia (1995), Lenci (1995), Lenci e Bertinetto (2000), Cunha (2006) e Bertinetto e Lenci (2012), para as frases habituais, essas configurações apresentam comportamentos linguísticos que as aproximam inequivocamente dos estativos (e.g. o tipo de interações que estabelecem com adverbiais temporais, com quantificadores sobre situações ou com verbos de operação aspectual), o que nos permite concluir que, nessas condições, o Imperfeito funciona, efetivamente, como um verdadeiro "estativizador". 9

intervalo do estado representado por "A Maria estar em Paris". Ora, sempre que temos o Imperfeito em subordinadas introduzidas por quando, o mesmo tipo de relação de inclusão é favorecido, ainda que as predicações básicas envolvidas sejam eventos (cf. numa frase como "Quando atravessava o jardim, a Maria telefonou ao filho", a leitura de inclusão parece evidente, i.e., o telefonema está localizado dentro dos limites temporais do intervalo ocupado por "A Maria atravessar o jardim"). Uma interpretação desse tipo contrasta com o que se passa quando o tempo gramatical escolhido é o Pretérito Perfeito, que, em $\mathrm{PE}$, parece ser aquele que revela maior neutralidade em termos aspectuais: assim, numa frase como "Quando atravessou o jardim, a Maria telefonou ao filho", deparamos tipicamente com uma relação de sucessividade, i.e., o telefonema só tem lugar após o atravessamento do jardim. Dados como esses fazem-nos acreditar que o Imperfeito, ao exibir comportamentos semelhantes aos dos estativos e distanciando-se do que se passa com os eventos prototípicos, manifesta marcas inequívocas de estatividade. Para mais argumentos nesse sentido, veja, por exemplo, Cunha (2004/2007).

${ }^{9}$ Para uma discussão aprofundada de alguns argumentos em favor do cariz estativo do Imperfeito em PE, veja-se, por exemplo, Cunha (2004/2007, 4.1.1.2). 
Finalmente, importa destacar que, para além dos seus valores temporais e aspectuais, o Imperfeito desempenha um papel crucial no que diz respeito à veiculação de informação de natureza modal. Com efeito, autores como Oliveira (1987), Travaglia (1987), Matos (1996), Cipria e Roberts (2000), Ippolito (2004), Ferreira (2004), Anand e Acquard (2009) ou Arregui, Rivero e Salanova (2014) defendem que a modalidade é parte essencial do núcleo semântico desse tempo gramatical. ${ }^{10}$ Nos seus usos modais, o Imperfeito remete, tipicamente, para a consideração de mundos possíveis, de alguma forma diferentes do designado mundo de referência, o que se traduz na emergência de leituras hipotéticas, potenciais ou não reais das proposições em causa.

Dentre os inúmeros valores modais que a literatura atribui ao Imperfeito, podemos destacar os seguintes: a) Imperfeito onírico ou ficcional, em que é descrito o conteúdo de sonhos ou de acontecimentos imaginários (cf. (7)); b) Imperfeito lúdico, normalmente associado a jogos e brincadeiras infantis (cf. (8)); c) Imperfeito hipotético, que dá conta de situações prováveis ou possíveis, mas que, por alguma razão ou impedimento, ainda não se verificaram no mundo real (cf. (9)); d) Imperfeito de cortesia, utilizado para atenuar a força ilocutória de ordens ou de pedidos (cf. (10)); e) Imperfeito de planificação, que projeta para o futuro uma situação que está a ser planeada ou preparada pelo locutor no momento da enunciação (cf. (11)):

(7) O João sonhou que tinha asas e que voava sobre a cidade.

(8) Agora chegavam os extraterrestres e nós fugíamos para a floresta.

(9) Eu telefonava à Maria (se tivesse comigo a agenda).

(10) Queria um bolo e um café, por favor.

(11) Então, amanhã, eu trazia um bolo e fazíamos uma festa! ${ }^{11}$

\footnotetext{
${ }^{10}$ Autores como Anand e Acquard (2009) ou Arregui, Rivero e Salanova (2014) chegam mesmo a defender que o núcleo semântico do Imperfeito seria essencialmente constituído por relações modais ("modal accessibilty relations"), sendo a componente temporal de passado obtida por meio de uma pressuposição de anterioridade.

${ }^{11}$ Embora o valor de planificação associado ao Imperfeito seja frequentemente invocado na literatura como um dos argumentos que reforçam a ideia de que esse tempo gramatical exprime futuridade, as análises divergem bastante a esse respeito.
} 


\subsection{O Condicional}

$\mathrm{Na}$ literatura sobre o Condicional, tem sido alimentada alguma controvérsia no que diz respeito ao seu tratamento semântico, sendo essa forma encarada ora como um tempo pertencente ao sistema do Indicativo, utilizado para exprimir posterioridade em relação a um dado intervalo passado, ora como um modo independente de pleno direito.

Uma hesitação dessa natureza em termos classificatórios reflete o facto bem conhecido de que o Condicional veicula tanto informação temporal quanto modal. Os autores que valorizam o seu caráter temporal incluem-no tipicamente no sistema do indicativo, denominando-o frequentemente "Futuro do Passado" (cf. e.g. CUNHA; CINTRA, 1984; PERES, 1993); aqueles que reconhecem a prevalência da sua natureza modal defendem a ideia de que estamos, efetivamente, perante um Modo Condicional autônomo (cf. OLIVEIRA; LOPES, 1995). Finalmente, há investigadores que, numa tentativa de conciliar essas duas perspectivas, propõem designações alternativas como a de "forma em -ria", que remete diretamente para a constituição morfológica da estrutura em causa, evitando, desse modo, tomar partido por uma das posições em confronto (cf. e.g. SILVA, 1997).

Cipria e Roberts (2000), por exemplo, defendem que, apesar de a eventualidade relevante estar localizada num intervalo posterior ao momento da enunciação, esse tipo de interpretação intencional não afeta obrigatoriamente a atribuição, comum a muitos outros casos, de uma perspectiva de anterioridade ao Imperfeito, na medida em que os autores consideram que o que aqui está em causa não é tanto a situação em si, mas antes a "intenção" que lhe está associada e que se localiza num intervalo que lhe é anterior. Por outras palavras, é a fase (pré)-preparatória, tal como descrita em Moens (1987) ou em Moens e Steedman (1988) que ocorre (e se localiza) num intervalo passado, sendo a situação principal projetada para um tempo indeterminado do futuro. Em favor desse ponto de vista, destaca-se o fato de que apenas construções inequivocamente intencionais podem receber uma interpretação deste gênero, como o contraste entre (i) e (ii) deixa transparecer:

(i) Eu amanhã telefonava ao cliente e resolvia o problema. (leitura intencional possível)

(ii) * Amanhã chovia. (leitura intencional impossível)

Como veremos mais adiante, esse tipo de contraste (i.e. intencional vs não intencional) não se revela relevante quando o Imperfeito exprime futuridade em relação a um PPT passado. 
Em qualquer dos casos, os gramáticos e linguistas que se dedicam ao estudo do Condicional estão de acordo quanto ao facto de que, reunidas as circunstâncias adequadas, essa forma pode exprimir tanto valores temporais quanto modais, embora, no estágio atual da língua, tal como demonstrado por Silva $(1997,3.2 .8)$ para o Português do Brasil, os usos de natureza modal pareçam ser prevalentes.

No que se refere à sua caracterização temporal, podemos dizer que o Condicional localiza as situações com que se combina num intervalo de tempo posterior em relação ao PPT passado a que se associa. Por outras palavras, o Condicional fornece informação de "futuro do passado" (cf. CUNHA; CINTRA, 1984) ou, seguindo a terminologia adotada por Declerck (1991, 2005), enquadra as eventualidades relevantes no setor posterior da esfera temporal do passado.

Tal como fizemos notar para o Imperfeito, o Condicional pode ser considerado, sob um certo ponto de vista, uma forma verbal de cariz eminentemente anafórico, na medida em que, para ser apropriadamente interpretado, requer a presença de um intervalo de tempo passado que lhe sirva como PPT, já que a sua significação temporal nunca pode ser computada de forma direta, tomando exclusivamente por base o tempo da enunciação.

Dada a necessidade da presença de um PPT passado para a sua interpretação, o Condicional com valor temporal é tipicamente encontrado em frases linearmente ordenadas no discurso (cf. 12)) ou em orações completivas de verbo (cf. (13)):

(12) O presidente chegou ao aeroporto às dez da manhã. Entraria no avião uma hora mais tarde.

(13) O presidente afirmou que responderia às perguntas dos jornalistas.

Assim, em (12), o evento "O presidente chegar ao aeroporto", representado num domínio passado, funciona como PPT para o Condicional, que localiza a situação a que se aplica, i.e., a entrada no avião, num intervalo que lhe é posterior. De forma semelhante, em (13), a oração principal no Pretérito Perfeito, "O presidente afirmou", constitui-se como o PPT passado com o qual o Condicional estabelece uma relação temporal de posterioridade para a localização da situação descrita na completiva, i.e., "responder às perguntas dos jornalistas". 
Uma consequência previsível da sua dependência obrigatória face a um intervalo passado manifesta-se no fato de o Condicional nunca estabelecer uma vinculação direta com o tempo da fala (speach time). Com efeito, e tal como salientado, e.g., em Oliveira e Duarte (2012), em Martínez-Atienza (2012) ou em Vatrican (2014), as eventualidades expressas no Condicional podem exibir livremente uma relação de anterioridade, de sobreposição ou de posterioridade com o momento da enunciação, como a plena compatibilidade com os diferentes adverbiais temporais em (14) deixa transparecer:

(14) (No passado sábado), o editor assegurou-me que o livro sairia ontem / hoje / amanhã.

Considerando que a eventualidade expressa pelo Condicional no caso em apreço "o livro sair" - é interpretada como temporalmente dependente do intervalo passado disponibilizado pela frase matriz, a sua ligação com o momento da enunciação será sempre alcançada de uma forma indireta, pelo que, a partir da relação de posterioridade que estabelece com o respectivo PPT, é possível que anteceda, que se sobreponha ou que siga o tempo da fala, como ilustrado em (14). Uma tal observação permite-nos concluir que, no contexto em apreço, a ordenação entre Tempo da Situação e Tempo da Fala se revela tipicamente indeterminada.

Para além da sua interpretação essencialmente temporal, o Condicional integra um vasto conjunto de valores de natureza eminentemente modal que importa ter em conta.

Um dos contextos em que o Condicional veicula valores de natureza modal é, sem dúvida, o das frases condicionais. Em PE, o Condicional surge frequentemente nas apódoses ${ }^{12}$ desse tipo de estruturas, manifestando um valor hipotético ou potencial quando se combina com o Imperfeito do Conjuntivo (cf. (15)):

(15) Se o crocodilo aparecesse no rio, os gnus fugiriam para a savana.

\footnotetext{
${ }^{12}$ Como se sabe, a apódose é a oração principal de uma frase condicional, cuja função primordial será a de apresentar uma ou mais consequências tidas como expectáveis. A prótase, por seu lado, é a oração subordinada, tipicamente introduzida pela conjunção se, que dá conta das condições consideradas necessárias para que a consequência esperada possa vir a ter lugar.
} 
O Condicional pode, igualmente, surgir em frases condicionais com valor contrafactual. Nesse caso, o verbo da prótase ocorre normalmente no Mais-que-Perfeito do Conjuntivo, tal como (16) nos revela:

(16) Se os leões tivessem corrido mais depressa, caçariam um gnu.

É importante sublinhar que, em qualquer dos casos (na sua leitura potencial ou na interpretação contrafactual), o Condicional expressa uma proposição que não teve lugar no mundo real ou no mundo de referência, ou seja, uma proposição que se inscreve no domínio do não realizado (cf. VATRICAN, 2014). Nessa medida, o Condicional manifesta aqui inequivocamente um valor de cariz modal que se substitui ao seu perfil temporal de posterioridade no passado.

Um outro uso modal tradicionalmente associado ao Condicional prende-se com a expressão da mitigação ou da cortesia. De acordo com Vatrican $(2013,2014)$, estamos na presença de um Condicional de cortesia quando essa forma verbal é usada para obter uma reação por parte do interlocutor. A referida interpretação ocorre sobretudo em configurações que envolvem solicitações ou pedidos indiretos, como ilustrado em (17). O Condicional de mitigação difere do de cortesia na medida em que se centra essencialmente no locutor. Neste último caso, a função central do Condicional será a de mitigar ou a de diminuir a força ilocutória de uma dada asserção (cf. (18)):

(17) Eu gostaria de uma bebida fresca. (= Por favor, dê-me uma bebida fresca)

(18) Eu diria que vamos ter um problema grave. (forma mitigada equivalente a $\mathrm{Eu}$ digo que vamos ter um problema grave)

Abouda (2001) sugere que o Condicional de mitigação se relaciona com outros usos modais dessa forma verbal, em particular os designados Condicional jornalístico e Condicional polêmico, constituindo uma categoria a que é dada a designação genérica de "Conditionnel de la non prise en charge" e que pode ser caracterizada pelo facto de o referido tempo verbal, nos contextos em causa, servir essencialmente para exprimir proposições cuja veracidade não é inteiramente assumida 
pelo locutor, ou seja, para dar conta de informação cujo valor de verdade não se encontra completamente confirmado ou assegurado.

Esses usos do Condicional são, portanto, geralmente caracterizados pela ausência de comprometimento por parte do falante em relação à factualidade das proposições expressas. A informação pode, assim, ser apresentada simplesmente como incerta ou não verificada no mundo de referência (cf. (19)) ou como proveniente de uma fonte externa ao locutor, caso em que nos encontramos perante o designado Condicional reportivo ou evidencial ${ }^{13}$ (cf. (20)):

(19) O terrorista estaria no hotel quando a bomba explodiu. (= o terrorista estava provavelmente no hotel quando a bomba explodiu)

(20) Segundo os jornalistas, o ministro teria mais de um milhão de euros em paraísos fiscais.

Sublinhe-se que, em casos como os apresentados nas frases (19) e (20), a informação temporal de posterioridade relativamente a um intervalo passado perde completamente a sua relevância e é suplantada pelo valor modal de incerteza. Em particular, a relação temporal mais frequente nesse tipo de sequências parece ser a de sobreposição a um intervalo passado (por exemplo, em (19), o estado descrito, i.e. "o terrorista estar no hotel", inclui - e, por conseguinte, sobrepõe-se a - o respectivo PPT fornecido pela oração temporal, "a bomba explodir"). O Condicional deixa, pois, de funcionar como expressão do futuro do passado para representar uma situação potencial que eventualmente teve lugar num intervalo anterior ao momento da enunciação.

Finalmente, importa assinalar um último uso modal do Condicional a que Martínez-Atienza (2012) chama Condicional de probabilidade e que Vatrican (2014) designa como Condicional de conjetura.

O Condicional de conjetura funcionaria como uma espécie de operador epistêmico de possibilidade. Ao contrário do que ocorre com os usos evidenciais, nesse caso é o próprio locutor que exprime o seu ponto de vista, perspectivando a ocorrência de uma dada eventualidade como uma possibilidade, como uma hipótese ou mesmo como uma

\footnotetext{
${ }^{13}$ Para uma análise mais detalhada do funcionamento do Condicional reportivo ou evidencial, vejam-se, entre outros, Dendale (2001), Squartini (2001) ou Vatrican (2014).
} 
probabilidade a ter em conta, em razão dos conhecimentos e informações de que dispõe acerca da realidade em que se insere. Um exemplo claro desse uso é oferecido em (21):

(21) A Maria faltou às aulas porque estaria doente.

Embora o uso conjetural do Condicional seja pouco frequente em PE e se encontre sujeito a diversas restrições - apenas estativos, por exemplo, parecem surgir sem problemas nesse tipo de configurações, obtendo-se a leitura de possibilidade epistêmica para os eventos por meio do recurso ao Condicional Perfeito -, é interessante observar que esse valor modal emerge também em construções que combinam probabilidade e concessão (cf. (22)), muito próximas dos exemplos que Martínez-Atienza (2012) invoca para o Espanhol.

O João teria pouco dinheiro, mas comprou um BMW.

Note-se que, mais uma vez, nos usos conjeturais do Condicional, não é a localização em termos de posterioridade de uma situação relativamente a um intervalo de tempo passado que está em causa (na verdade, em muitos dos casos, encontramo-nos face a uma relação de sobreposição a um PPT passado), mas antes uma interpretação que conduz à expressão da hipótese ou da probabilidade, ou, dito de outra forma, para a não concretização do conteúdo proposicional descrito no mundo real, o que indica que estamos perante mais um caso de manifestação da modalidade (cf. PORTNER, 2009).

\subsection{Ir no Imperfeito + Infinitivo}

A construção ir no Imperfeito + Infinitivo partilha um conjunto bastante significativo de propriedades semânticas com o Condicional, em particular no que diz respeito à sua caracterização temporal. Com efeito, e tal como observamos para o Condicional, a estrutura ir no Imperfeito + Infinitivo possibilita localizar uma situação num intervalo posterior ao Ponto de Perspectiva Temporal passado com que se combina, ou seja, exprime uma relação que pode ser descrita como a de "futuro do passado" (cf. PERES, 1993).

Tratando-se de uma forma verbal de cariz anafórico, i.e., que estipula a presença de um intervalo diferente do momento da enunciação 
para ser adequadamente interpretada, ir no Imperfeito + Infinitivo surge preferencialmente no contexto de orações encaixadas - caso em que o intervalo relevante é fornecido pela situação da matriz (cf. (23)) - ou em frases sequencialmente ordenadas num discurso de tipo narrativo - caso em que será uma das eventualidades descritas a disponibilizar o PPT requerido (cf. (24)):

(23) Os bombeiros avisaram que o edifício ia ruir.

(24) O edifício foi construído em 1999. Ia ruir dois anos mais tarde por causa de um grande incêndio.

Mais uma vez, dado que a estrutura ir no Imperfeito + Infinitivo determina que a situação com que se combina se encontre ligada a um intervalo passado que lhe serve de PPT, não sendo viabilizada qualquer relação direta com o momento da enunciação, é perfeitamente possível encontrar casos em que se verifica anterioridade, sobreposição ou posterioridade com o tempo da fala, como a compatibilidade com adverbiais temporais dêiticos que remetem para o passado (cf. ontem), para o presente (cf. hoje) ou para o futuro (cf. amanhã) deixa transparecer: ${ }^{14}$

(25) (No sábado), a Maria disse que ia assistir a uma conferência ontem / hoje / amanhã.

O fato de a estrutura ir no Imperfeito + Infinitivo desencadear uma relação temporal de posterioridade num domínio passado abre caminho para a possibilidade da sua associação com interpretações de cariz modal, na medida em que, como é frequentemente reconhecido na literatura, a projeção para o futuro envolve invariavelmente um certo grau de incerteza e, assim, a necessidade de consideração de "ramificações" que remetem para diferentes mundos possíveis (veja-se a noção de inertia worlds proposta por DOWTY, 1979).

Nesse sentido, Cunha (2015) sugere que, para além da sua interpretação puramente temporal, a construção ir no Imperfeito + Infinitivo pode igualmente dar lugar a leituras modais de tipo hipotético. Nessas circunstâncias, as proposições expressas não ocorrem

\footnotetext{
${ }^{14}$ A única restrição relevante nesses casos é, naturalmente, que a situação em causa se verifique num intervalo posterior ao respectivo Ponto de Perspectiva Temporal passado.
} 
obrigatoriamente no mundo de referência, mas são concebidas como meras hipóteses ou possibilidades a ter em conta em determinados mundos alternativos.

Ora, tomando em consideração que, como já referimos, a configuração sob análise não estabelece uma relação direta com o momento da enunciação, não é difícil conceber contextos em que a situação que é projetada para o futuro a partir de um PPT passado ainda não tenha tido lugar no momento da fala, sendo, por conseguinte, impossível avaliar a veracidade da sua ocorrência em $t 0,{ }^{15}$ o que, naturalmente, favorece a emergência de interpretações de natureza modal.

Parece-nos, pois, lícito concluir que os usos modais associados a ir no Imperfeito + Infinitivo derivam, em grande medida, das propriedades temporais que caracterizam essa estrutura. Como teremos oportunidade de constatar mais adiante, esse fato poderá ajudar-nos a compreender melhor as divergências, em termos de comportamento linguístico, no contexto de orações completivas de verbo, que se podem observar entre a configuração em causa e o Condicional, forma que manifesta valores modais bem mais abrangentes.

No que diz respeito às interpretações modais desencadeadas pela configuração ir no Imperfeito + Infinitivo, podemos distinguir dois casos principais: (i) a situação pode ser perspectivada como não tendo sido ainda realizada no mundo de referência, mas encarada, ainda assim, como uma possibilidade ou como uma hipótese a ter em conta no curso futuro dos acontecimentos (cf. (26)); (ii) ou ela pode ser concebida como irrealizável, i.e., como inscrita num domínio que se encontra inteiramente fora da realidade (cf. (27)). Essa última leitura corresponderia aos usos contrafactuais que Martín (2008) atribui à construção ir a no Imperfeito + Infinitivo do Espanhol.

(26) O presidente da empresa garantiu que ia aumentar o salário dos seus funcionários.

(27) O presidente da empresa ia aumentar o salário dos seus funcionários quando a companhia entrou em falência.

${ }^{15}$ Utilizaremos, ao longo do presente trabalho, a notação t0 para indicar o tempo da enunciação ou momento da fala e $w 0$ para aludir ao mundo de referência ou mundo real. 
Sublinhe-se que a atribuição de uma interpretação hipotética ou contrafactual às frases envolvendo a construção ir no Imperfeito + Infinitivo depende essencialmente do contexto (linguístico ou extralinguístico) em que os enunciados são produzidos. Na verdade, numa grande parte dos casos, não dispomos de informação suficiente para saber se a situação em causa irá ou não ter lugar no mundo real. Por exemplo, num enunciado como o de (25), a indicação de que a companhia entrou em falência direciona de forma bem clara para uma leitura contrafactual da proposição "O presidente da empresa aumentar o salário dos seus funcionários". ${ }^{16}$ No entanto, se procedermos a algumas alterações no contexto em que se insere a proposição sob análise, é possível obter uma sequência em que a interpretação preferencial é a de possibilidade, tal como ilustrado em (28):

(28) O presidente da empresa ia aumentar o salário dos seus funcionários, mas, antes disso, precisa consultar os acionistas.

Em suma, concluímos que a construção ir no Imperfeito + Infinitivo, dadas as circunstâncias adequadas, desencadeia interpretações de cariz modal, que tanto podem tender para a possibilidade quanto para a contrafactualidade, dependendo de fatores contextuais como o tipo de informação que se encontra disponível ou as características das diferentes orações que com ela interagem no discurso.

No que se refere à análise da construção ir no Imperfeito + Infinitivo, seguiremos a proposta de Cunha (2015) segundo a qual as suas interpretações temporais e modais podem ser unificadas sob uma mesma descrição semântica. Assim, independentemente do valor de verdade a atribuir às proposições no seu escopo, ir no Imperfeito + Infinitivo parece veicular consistentemente um significado temporal de posterioridade em relação a um dado intervalo passado. Na realidade, mesmo as proposições que expressam valores modais - hipotéticos ou contrafactuais - preservam tipicamente a informação temporal de posterioridade no passado, tal como ilustrado no seguinte exemplo:

(20) A Maria ia ligar a televisão quando o telefone tocou.

\footnotetext{
${ }^{16}$ De um modo geral, podemos afirmar que a comparência de frases de natureza contrastiva exibindo tempos do passado favorece uma leitura contrafactual para as configurações que integram a estrutura ir no Imperfeito + Infinitivo.
} 
Ainda que a proposição expressa por "A Maria ligar a televisão" não seja de todo verdadeira no mundo real, o que é certo é que ela parece estabelecer uma relação consistente de posterioridade com o intervalo em que ocorre a situação descrita pela oração introduzida por quando, o que nos leva a acreditar que, mesmo nos casos em que uma interpretação modal é preponderante, as interdependências de natureza temporal que caracterizam a construção sob análise se mantêm, em certa medida, inalteradas. Ou seja, a relação de posterioridade no passado é sempre preservada, independentemente de a eventualidade em apreço ocorrer ou não no mundo de referência.

Com base nas observações que acabamos de efetuar, encontramonos finalmente em posição de propor a seguinte formulação para a caracterização semântica da estrutura analisada na presente subsecção: (i) ir no Imperfeito + Infinitivo exprime uma relação temporal consistente e obrigatória de posterioridade em relação a um determinado Ponto de Perspectiva Temporal passado; (ii) a diferença que se pode observar entre as duas principais interpretações associadas a essa construção deriva do fato de que, em certos casos, a situação descrita é considerada verdadeira no mundo de referência (leitura temporal) e, noutros, o seu valor de verdade está indeterminado ou chega mesmo a ser concebido como falso em $w 0$, sendo necessário o recurso à noção de mundos alternativos para a sua adequada computação (leitura modal).

Por outras palavras, ir no Imperfeito + Infinitivo recebe um valor positivo para o traço temporal de [posterioridade], sendo indeterminado no que se refere à atribuição dos valores de verdade às situações com que se combina. Ou seja, em qualquer caso, estamos perante um futuro do passado, podendo as eventualidades ser verdadeiras no mundo real ou inscritas em mundos alternativos (inertia worlds). ${ }^{17}$

\footnotetext{
${ }^{17}$ Nesse sentido, advogamos para o Português Europeu um tratamento eminentemente temporal da estrutura ir no Imperfeito + Infinitivo, na esteira de trabalhos como os de Rodrigues (2011) para o PB ou os de Oliveira e Duarte (2012) e Cunha (2015) para o PE. O caso do espanhol aparenta ser algo diferente, já que um tratamento no âmbito aspectual em termos de Aspecto Prospectivo se revela a opção preferida pelos linguistas que refletem sobre essa questão (cf. MARTÍN, 2008; BURGOS, 2013). No entanto, não parecem existir em PE evidências que justifiquem a adoção desse tipo de abordagem que, mesmo na literatura sobre o espanhol, suscita algumas dúvidas, críticas e oscilações.
} 


\section{A expressão da futuridade em orações completivas de verbo}

Até ao momento, e com base na caracterização que propusemos para os três tempos gramaticais em apreço, constatamos que tanto o Imperfeito como o Condicional e a construção ir no Imperfeito + Infinitivo se revelam capazes de exprimir a localização de uma eventualidade num intervalo futuro em relação a um dado PPT situado na esfera do passado. Verificámos igualmente que partilham a possibilidade de induzir interpretações de cariz modal às proposições a que se aplicam. Isso não significa, no entanto, que as referidas formas verbais se revelem semanticamente idênticas entre si. Como tivemos oportunidade de verificar, o Imperfeito é essencialmente um tempo que se caracteriza pela sobreposição a um dado intervalo passado, sendo os seus valores futurativos e modais obtidos em circunstâncias muito específicas; o Condicional, por seu lado, embora capaz de estabelecer uma relação temporal de posterioridade no passado, exprime fundamentalmente modalidade, ao passo que ir no Imperfeito + Infinitivo reporta primariamente uma relação temporal de futuridade em relação a um determinado PPT passado, sendo as suas leituras modais derivadas desse seu perfil temporal básico e, nesse sentido, sujeitas a um número bastante significativo de restrições.

Um contexto em que essas diferenças e similaridades são particularmente visíveis é, sem dúvida, o das orações completivas de verbo, na medida em que a situação da frase matriz fornece um Ponto de Perspectiva Temporal explícito em relação ao qual a proposição da subordinada vai ser localizada. Nesse sentido, dedicaremos a presente seção deste trabalho à análise das possibilidades interpretativas manifestadas pelo Imperfeito, pelo Condicional e pela estrutura ir no Imperfeito + Infinitivo em orações encaixadas subcategorizadas por diferentes tipos de verbos introdutores.

Com o objetivo de determinar o papel desempenhado pelos diferentes elementos linguísticos que interagem na determinação das interpretações prospectivas dos tempos gramaticais que temos vindo a discutir, propomo-nos, nas páginas que se seguem, explorar as leituras mais relevantes ostentadas pelas orações completivas associadas a quatro categorias de verbos introdutores: (i) verbos como dizer ou afirmar, que, por si só, parecem não condicionar grandemente a localização temporal das eventualidades na subordinada com que se combinam; (ii) verbos 
como prometer ou decidir, que, em certa medida, induzem orientação para o futuro; (iii) verbos de cariz factivo como constatar ou descobrir, que requerem tipicamente a veracidade da proposição no seu escopo e (iv) verbos intensionais como imaginar, sonhar ou acreditar, que favorecem leituras não verídicas das proposições com que coocorrem. ${ }^{18}$

\subsection{Verbos dicendi: dizer e afirmar}

Começaremos a nossa análise do comportamento do Imperfeito, do Condicional e de ir no Imperfeito + Infinitivo no contexto de completivas por estruturas que integram verbos como dizer ou afirmar, que parecem ser aqueles que menos condicionam a localização temporal das situações representadas na subordinada.

Com efeito, seguindo propostas como as avançadas por Cunha e Silvano (2006), considerarei aqui que esses verbos são temporalmente "neutros", no sentido em que as eventualidades por eles subcategorizadas não se encontram sujeitas a restrições específicas no que se refere à sua localização temporal. Assim, tal como os exemplos que se seguem nos confirmam, as situações que se combinam com verbos como dizer ou afirmar tanto podem ocorrer num período de tempo anterior (cf. (30)), sobreposto (cf. (31)) ou posterior (cf. (32)) ao intervalo em que decorre o evento da oração matriz, dependendo do tempo gramatical selecionado.

(30) O jornalista disse que entrevistou / tinha entrevistado o Presidente da República. (anterioridade)

(31) O jornalista disse que estava a entrevistar o Presidente da República. (sobreposição)

(32) O jornalista disse que ia entrevistar o Presidente da República. (posterioridade)

Exemplos como os que acabamos de apresentar parecem demonstrar que verbos do gênero de dizer ou de afirmar não afetam

\footnotetext{
18 Dado que o nosso objetivo, de momento, é apenas o de tentar compreender os constrangimentos que condicionam as interpretações futurativas no contexto de certas orações completivas de verbo, não nos será possível, naturalmente, fornecer uma panorâmica geral do funcionamento semântico desse tipo de construções em PE. Para uma discussão mais aprofundada do tema, veja-se Silvano (2002).
} 
diretamente a localização temporal das situações com que se combinam, na medida em que elas podem surgir, livremente, antes, durante ou depois do respectivo PPT, aqui fornecido pela frase matriz.

Tendo em conta essas observações, será de prever que as propriedades semânticas básicas dos diferentes tempos gramaticais envolvidos em completivas introduzidas por dizer ou por afirmar sejam globalmente preservadas na interpretação final desse tipo de configurações. Como veremos em seguida, essa predição parece confirmar-se, pelo menos para formas verbais como o Imperfeito, o Condicional e ir no Imperfeito + Infinitivo.

Como referimos em 2.1, o Imperfeito, em geral, localiza a situação a que se aplica num intervalo de tempo que coincide, total ou parcialmente, com um dado PPT passado, i.e., estabelece preferencialmente uma relação de sobreposição num domínio temporal [+passado] (cf. DECLERCK, 1991; PERES, 1993).

Se considerarmos frases completivas encabeçadas por dizer ou afirmar em que a subordinada exprime uma predicação de cariz estativo, essa relação de sobreposição parece, de fato, ser a mais natural, tal como ilustrado em (33) e (34): ${ }^{19}$

$$
\begin{aligned}
& \text { A Maria disse que o João vivia em Paris. }(e 1 \text { o } e 2) \\
& \text { O entrevistado afirmou que era escritor. }(e 1 \text { o } e 2)^{20}
\end{aligned}
$$

Nesses exemplos, os estados representados na subordinada, nomeadamente "O João viver em Paris" e "[o entrevistado] ser escritor", ocupam um intervalo que coincide parcialmente com o tempo passado estabelecido pelas proposições nas respectivas frases matriz. ${ }^{21}$

\footnotetext{
${ }^{19}$ A observação de que, em PE, os estados no Imperfeito se sobrepõem ao intervalo de tempo fornecido pelo verbo matriz em construções completivas envolvendo dizer ou afirmar é relativamente consensual na literatura, tendo já sido efetuada por autores como Oliveira (1998), Silvano (2002) ou, mais recentemente, Oliveira e Duarte (2012). ${ }^{20}$ A notação que usamos nesses e nos próximos exemplos é a seguinte: el representa a eventualidade da oração principal; e2, a da subordinada; o, uma relação temporal de sobreposição; <uma relação de anterioridade e>, uma relação de posterioridade.

${ }^{21}$ Tratando-se, tipicamente, de uma interação entre eventos (na principal) e estativos (na subordinada), a relação temporal de inclusão parece ser a preferida nesses contextos (para uma explicação mais detalhada, vejam-se, a esse respeito, as propostas de KAMP; ROHRER, 1983 e de KAMP; REYLE, 1993).
} 
Quando, porém, na oração subordinada de completivas introduzidas por dizer ou afirmar surgem eventos, a computação das suas possibilidades interpretativas torna-se bastante mais complexa. $\mathrm{Na}$ realidade, e como já procuramos deixar claro anteriormente, o Imperfeito funciona, tipicamente, como um estativizador, ou seja, converte os eventos com que se combina em predicações derivadas de natureza estativa (cf. os argumentos avançados, entre outros, por KAMP; ROHRER, 1983; OLIVEIRA; LOPES, 1995; MATOS, 1996; CUNHA, 2004/2007).

Nesse sentido, a relação de sobreposição no passado que caracteriza o Imperfeito é, naturalmente, preservada também nesses contextos, desde que os eventos básicos que neles tomam parte tenham sido previamente convertidos ou em estados habituais ou em estados semiprogressivos. Os exemplos que se seguem ilustram o que acabamos de expor: os eventos das subordinadas em (35) e (36), graças à intervenção de um mecanismo de repetição de situações, são perspectivados como estruturas que descrevem rotinas ou hábitos, ao passo que os de (37) e (38), que apenas são encarados como prolongando-se indefinidamente no tempo, sem referência aos seus momentos inicial ou final, assemelhamse às construções de cariz progressivo. Em qualquer dos casos, a interpretação de sobreposição no passado parece ser a mais adequada para dar conta das interdependências temporais presentes nestas frases.

(35) O João disse que jogava tênis (= tinha o hábito de jogar tênis). $(e 1$ o $e 2)$

(36) O jornalista afirmou que entrevistava pessoas famosas (= costumava entrevistar pessoas famosas). $(e 1 \mathrm{o} e 2)$

(37) A Maria disse que as crianças brincavam no jardim (= estavam a brincar no jardim). (el o e2)

(38) Os bombeiros afirmaram que as chamas consumiam a floresta (= estavam a consumir a floresta). $(e 1 \mathrm{o} e 2)$

Em todas essas frases parece existir uma relação de sobreposição entre os tempos em que decorrem as eventualidades na subordinada e o PPT passado fornecido pela frase matriz. Assim, por exemplo, em (36), o intervalo em que o jornalista entrevista pessoas famosas começa antes e prolonga-se para além do tempo em que ele faz a afirmação, i.e., 
observa-se aqui uma relação de inclusão temporal semelhante à que observamos para os estados básicos em (33) e (34). O mesmo se passa com os exemplos de leituras semiprogressivas: em (37), o tempo em que a Maria fez a sua afirmação está incluído - e, nesse sentido, encontra-se também sobreposto - no intervalo em que as crianças brincam no jardim.

Embora a relação de sobreposição a um tempo passado pareça ser preferencial no caso do Imperfeito no contexto de completivas introduzidas por dizer ou afirmar, na medida em que pode ser obtida com todas as classes aspectuais de predicações, mesmo que os eventos tenham de ser previamente convertidos em estados de natureza derivada, é igualmente possível encontrar casos em que ocorre posterioridade no interior de um domínio passado. ${ }^{22}$

As leituras prospectivas com o Imperfeito em completivas introduzidas por verbos relativamente "neutros" em termos da localização temporal da subordinada encontram-se, no entanto, sujeitas a algumas restrições que importa destacar.

Se é certo que será suficiente a presença de um adverbial temporal prospectivo para o licenciamento de interpretações desse tipo quando estão em causa predicações eventivas, os estados parecem ser sistematicamente excluídos, tal como o contraste entre (39) e (40), com eventos, e (41) e (42), com estados, nos indica:

(39) A Maria disse que chovia amanhã / daí a dois dias. $(e 1<e 2)$

(40) O presidente afirmou que entregava o relatório amanhã / daí a dois dias. ${ }^{23}(e 1<e 2)$

(41) * A Maria disse que estava doente amanhã / daí a dois dias. $(e 1<e 2)$

(42) * O presidente afirmou que vivia nos Estados Unidos amanhã / daí a dois dias. $(e 1<e 2)$

\footnotetext{
${ }^{22}$ Essa possibilidade foi já referida na literatura para o PE, por exemplo, em Oliveira (1998), Silvano (2002) e Oliveira e Duarte (2012).

${ }^{23}$ Note-se, de passagem, que, no contexto de leituras prospectivas do Imperfeito, os eventos representados parecem manter as suas propriedades aspectuais básicas inalteradas, não sendo convertidos em estados de tipo derivado.
} 
Na ausência de adverbiais temporais prospectivos, são igualmente possíveis leituras futurativas do Imperfeito com eventos, desde que estes se encontrem associados a algum tipo de intencionalidade ou de planificação (cf. CIPRIA; ROBERTS, 2000). Observe-se o seguinte contraste, em que apenas numa frase como (43), que manifesta algum tipo de planificação, o Imperfeito pode receber uma leitura de posterioridade no passado, sendo esse tipo de interpretação completamente excluída em (44), que não exibe essas características:

O João disse que entregava a tese. $(e 1<e 2)$

(44) \# O João disse que partia o braço. $(e 1<e 2)$

Os dados que acabamos de discutir sugerem, pois, que a leitura preferencial para o Imperfeito no contexto de completivas introduzidas por verbos relativamente neutros no que toca à localização temporal da subordinada, do gênero de dizer ou de afirmar, será a de sobreposição ao respectivo PPT passado, sendo as interpretações de cariz futurativo viabilizadas apenas em condições bastante particulares, nomeadamente na presença de adverbiais prospectivos ou em configurações em que a intencionalidade ou a planificação se revelam muito evidentes. ${ }^{24}$

Contrariamente ao que sucede com o Imperfeito, o Condicional, no contexto de verbos introdutores temporalmente neutros, como dizer ou afirmar, parece receber uma interpretação consistente de posterioridade no passado, independentemente da classe aspectual da situação representada na subordinada. Por outro lado, e tal como notado em Oliveira e Duarte (2012), esse tempo gramatical veicula adicionalmente informação de natureza modal associada à presença de uma oração condicional implícita. Sob esse ponto de vista, o Condicional combina, nas configurações sob análise, propriedades temporais e modais, como nos sugerem os seguintes exemplos:

\footnotetext{
${ }^{24}$ Excluímos desta nossa análise, naturalmente, os casos em que dizer não se assume como um verdadeiro verbo "reportivo" e é lexicalmente equivalente a formas do gênero de prometer ou de comprometer-se. Nessas circunstâncias, o seu comportamento semântico será semelhante ao dos verbos que abordarei na próxima subsecção deste trabalho. Em particular, pode mesmo surgir com estativos numa leitura prospectiva como em "O ministro disse (= prometeu) que estava no parlamento amanhã".
} 
(45) O João disse que compraria um BMW (se tivesse dinheiro suficiente). $(e 1<e 2)$

(46) O ministro afirmou que aumentaria os salários (se o país recebesse fundos da União Europeia). $(e 1<e 2)$

(47) A Maria disse que seria professora (se conseguisse concluir o curso). $(e 1<e 2)$

(48) O escritor afirmou que viveria em Paris (se tivesse de abandonar a sua terra natal). $(e 1<e 2)$

Em todas essas frases a situação descrita pelo verbo na oração matriz fornece o intervalo passado que se constitui como Ponto de Perspectiva Temporal para a localização das eventualidades na subordinada, que, independentemente do seu perfil aspectual, estabelecem com o referido PPT uma relação de posterioridade. Assim, por exemplo, o estado descrito por "[A Maria] ser professora" em (47), a realizar-se, será sempre concebido como posterior ao evento introduzido por "A Maria dizer".

Por outro lado, tendo em conta que, tal como observamos em 2.2, o Condicional se revela particularmente apto para a expressão de valores modais, não surpreende que as construções que aqui estamos analisando surjam frequentemente associadas a orações condicionais implícita ou explicitamente realizadas. De fato, e pelo menos no entender de alguns falantes do Português Europeu, a total supressão da oração condicional nos contextos em questão conduz frequentemente à sensação de incompletude da estrutura ou mesmo a um certo grau de anomalia.

Uma outra observação que reforça a ideia de que o Condicional, para além do seu valor temporal, veicula fundamentalmente uma significação de cariz modal está relacionada ao fato de que, no contexto de completivas introduzidas por dizer ou afirmar, essa forma viabiliza leituras reportivas ou evidenciais, típicas do designado uso de "incerteza" ou de "informação não confirmada" que lhe é habitualmente atribuído (cf. ABOUDA, 2001). Vejam-se os seguintes exemplos:

(49) Os pastores disseram que os lobos estariam na aldeia. ( $e 1$ o e2)

(50) Os jornalistas afirmaram que o ministro possuiria dinheiro no estrangeiro. ( $e 1$ o $e 2)$ 
É interessante constatar que, nas interpretações em que o Condicional exprime sobretudo incerteza ou informação não confirmada, não se observa a relação temporal de posterioridade com o PPT passado fornecido pela frase matriz, que, como já referimos, normalmente caracteriza essa forma verbal. Nesses casos, o Condicional exprime essencialmente um valor modal "potencial", ou seja, indica que a informação veiculada pela proposição da oração subordinada não é certa ou não se encontra ainda confirmada, embora constitua uma possibilidade em aberto. Como uma consequência desse valor modal, a relação temporal que se estabelece entre as situações referidas é tipicamente a de sobreposição, o que indicia que a contribuição em termos de modalidade associada ao Condicional acaba por suplantar as suas propriedades temporais básicas.

Paralelamente ao que sucede com o Condicional, a construção ir no Imperfeito + Infinitivo, no contexto de completivas introduzidas por verbos como dizer ou afirmar, induz uma leitura de posterioridade em relação ao respectivo PPT passado, seja qual for a classe aspectual da situação descrita, como ilustrado nos exemplos que se seguem:

(51) O João disse que ia comprar um BMW. (evento) $(e 1<e 2)$

(52) O ministro afirmou que ia aumentar os salários. (evento) $(e 1<e 2)$

(53) A Maria disse que ia ser professora. (estado) $(e 1<e 2)$

(54) $\mathrm{O}$ escritor afirmou que ia viver em Paris. (estado) $(e 1<e 2)$

Em todas essas frases as proposições da subordinada são localizadas num intervalo ulterior ao PPT fornecido pela situação descrita na matriz, estabelecendo-se consistentemente uma relação de posterioridade no passado. No entanto, e ao contrário do que sucede com o Condicional, a construção ir no Imperfeito + Infinitivo pode veicular informação puramente temporal de futuridade no passado, não requerendo a presença, implícita ou explícita, de uma oração condicional para a sua plena interpretabilidade. Não queremos com isso afirmar, contudo, que a estrutura ir no Imperfeito + Infinitivo não possa estar envolvida em interpretações de natureza modal, o que, aliás, sucede com alguma frequência, mas simplesmente que a modalidade parece não estar 
intrinsecamente associada às leituras que essa forma desencadeia no contexto de completivas introduzidas por verbos como dizer ou afirmar.

Por outro lado, as condições em que ir no Imperfeito + Infinitivo envolve valores modais diferem substancialmente daquelas que tivemos oportunidade de destacar para o Condicional. Em particular, como (55) e (56) demonstram, ir no Imperfeito + Infinitivo entra essencialmente em configurações que exprimem contrafactualidade, semelhantes às que Martín (2008) reconhece para a construção equivalente do Espanhol:

(55) O João disse que ia comprar um BMW, mas não teve dinheiro suficiente para o fazer. $(e 1<e 2)$

(56) O ministro afirmou que ia aumentar os impostos mas desistiu por causa das manifestações. $(e 1<e 2)$

É importante sublinhar que, nessas frases, a relação temporal de posterioridade no passado parece estar plenamente preservada (i.e., por exemplo, "[o João] comprar um BMW" é necessariamente concebido como posterior a "O João dizer"). Na verdade, a única particularidade que as distingue relaciona-se ao fato de que a proposição representada na subordinada não se atualiza no designado mundo real ou $w 0$, sendo, em vez disso, avaliada em relação a um mundo possível alternativo. ${ }^{25}$

Um último argumento a favor da ideia de que a estrutura ir no Imperfeito + Infinitivo, no contexto de completivas introduzidas por verbos temporalmente neutros, preserva o seu significado básico de posterioridade no passado diz respeito ao fato de essa forma, contrariamente ao que sucede, por exemplo, com o Condicional, não tolerar interpretações evidenciais, reportivas ou de "incerteza", na medida em que as referidas leituras favoreceriam, tipicamente, uma relação de sobreposição ao PPT passado. Observem-se os seguintes exemplos ilustrativos:

(57) Os pastores disseram que os lobos iam estar na aldeia. (*el o e2)

(58) Os jornalistas afirmaram que o ministro ia possuir dinheiro no estrangeiro. $(*$ e 1 o $e 2)$

\footnotetext{
${ }^{25}$ Para uma discussão um pouco mais aprofundada sobre essa questão, ver Cunha (2015).
} 
A serem interpretáveis, frases como (57) e (58) apenas poderão receber leituras de posterioridade no passado, i.e., por exemplo, em relação a (57), uma interpretação em que a permanência dos lobos na aldeia é inteiramente posterior ao intervalo em que ocorre a afirmação produzida pelos pastores.

Em suma, é possível concluir que os dados referentes ao comportamento do Imperfeito, do Condicional e da estrutura ir no Imperfeito + Infinitivo no contexto de verbos introdutores de completivas relativamente neutros, em termos de localização temporal, como dizer ou afirmar, sugerem a preservação de uma grande parte das propriedades semânticas básicas de cada um desses tempos gramaticais. Nesse sentido, as configurações com o Imperfeito revelam uma tendência notória para a sobreposição no passado, sendo as leituras futurativas igualmente possíveis, embora sob certas condições específicas; o Condicional está essencialmente envolvido em interpretações de cariz modal, seja pela associação a orações de tipo condicional, seja pela expressão da evidencialidade ou da possibilidade; finalmente, a estrutura ir no Imperfeito + Infinitivo exprime consistentemente a posterioridade em relação a um PPT passado, mesmo que esta se encontre articulada com valores modais como o de contrafactualidade.

\subsection{Verbos orientados para o futuro: prometer e decidir}

Verbos como prometer ou decidir diferem consideravelmente de dizer ou de afirmar na medida em que impõem interpretações futurativas às situações que ocorrem nas suas subordinadas. Por outras palavras, e tal como, de resto, já foi observado em Cunha e Silvano (2006), esses verbos influenciam decisivamente a localização temporal das eventualidades que subcategorizam, conferindo-lhes uma leitura obrigatória de posterioridade.

Não surpreende, por isso mesmo, que interpretações que não contemplem, de forma clara, uma relação de posterioridade sejam completamente impossíveis com verbos como prometer ou decidir, tal como os seguintes exemplos nos comprovam:

* O João prometeu que telefonou / tinha telefonado à Maria. (anterioridade)
* O João prometeu que estava a telefonar à Maria. (sobreposição) 
(61) O João prometeu que ia / vai telefonar à Maria. (posterioridade)

(62) * A mãe decidiu que a Rita estudou / tinha estudado japonês. (anterioridade)

(63) * A mãe decidiu que a Rita estava a estudar japonês. (sobreposição)

(64) Amãe decidiu que a Rita ia / vai estudar japonês. (posterioridade)

Uma consequência previsível dessa caracterização sugere que as formas do Imperfeito, do Condicional e de ir no Imperfeito + Infinitivo, quando combinadas com verbos como prometer ou decidir, apenas possam ser licenciadas em contextos em que se verifica uma interpretação de posterioridade no passado. Vejamos se essa predição se confirma efetivamente.

Começando pelo Imperfeito, observamos que, quando, na subordinada de verbos como prometer ou decidir, estão em causa predicações de cariz eventivo, uma leitura de posterioridade no passado é facilmente obtida (cf. (65)-(66)), sendo, de resto, a única alternativa viabilizada:

(65) O ministro prometeu que falava com os jornalistas. $(e 1<e 2)$

(66) Os bombeiros decidiram que abandonavam o local. $(e 1<e$ 2)

Pelo contrário, os estativos no Imperfeito parecem ocasionar anomalia semântica quando combinados com verbos como prometer ou decidir, tal como notado por Oliveira e Duarte (2012). Esse resultado deve-se provavelmente ao fato de que, com estados, a leitura de sobreposição no passado é praticamente obrigatória, o que entra em conflito com as propriedades semânticas que caracterizam os verbos introdutores sob análise. ${ }^{26}$

\footnotetext{
${ }^{26}$ Refira-se, no entanto, que, com certos tipos de estativos, nomeadamente com os designados estados faseáveis (cf. CUNHA, 2004/2007), é possível encontrar construções envolvendo verbos do tipo de prometer ou decidir que se revelam bastante mais aceitáveis, ostentando uma interpretação prospectiva, como ilustrado em (i) e (ii). Por vezes, a aceitabilidade destas frases melhora consideravelmente se a elas for associado um adverbial temporal prospectivo.
} 
* A Joana prometeu que era médica.

(68) * A Maria decidiu que estava grávida.

Tomando em consideração que o Condicional, por si só, é capaz de desencadear uma localização de posterioridade em relação a um PPT passado, não surpreende que ele ocorra livremente no contexto de subordinadas introduzidas por verbos orientados para o futuro, do gênero de prometer ou de decidir, independentemente da classe aspectual das predicações envolvidas (cf. (69)-(70) com eventos e (71)-(72) com estados), embora, na maioria das vezes, e tal como observamos para as completivas com dizer e afirmar, surja associado a uma oração de tipo condicional com valor claramente modal.

(69) O ministro prometeu que falaria com os jornalistas (se a situação política assim o exigisse). $(e 1<e 2)$

(70) Os bombeiros decidiram que abandonariam o local (se a sua segurança estivesse posta em causa). $(e 1<e 2)$

(71) A Joana prometeu que seria médica (se esse fosse o desejo dos seus pais). $(e 1<e 2)$

(72) O João decidiu que viveria em Paris (se fosse obrigado a emigrar). $(e 1<e 2)$

Em qualquer dos exemplos apresentados anteriormente, a situação associada ao verbo matriz, que se constitui como o PPT relevante, é tomada como ocorrendo num intervalo anterior ao da eventualidade representada na subordinada, independentemente de esta vir ou não a ser realizada no mundo de referência, o que significa, em última instância, que estamos perante casos de posterioridade no passado.

(i) ? A Maria prometeu que era simpática com os colegas (na festa que vai dar amanhã).

(ii) ? O João decidiu que vivia em Paris.

Dado que, no presente texto, não nos é possível debater a questão da faseabilidade em toda a sua extensão, não nos alongaremos mais na discussão desses exemplos, afirmando apenas que a subclasse de estativos em apreço manifesta um comportamento muito próximo do que caracteriza os eventos. 
Leituras evidenciais ou de possibilidade que, de alguma forma, envolvam a sobreposição da situação da subordinada ao PPT fornecido pela frase matriz são, no caso de verbos como prometer ou decidir, completamente descartadas, mesmo que se revelem perfeitamente compatíveis com as propriedades semânticas do Condicional, como já observamos anteriormente. Uma restrição desse tipo deve-se, naturalmente, aos pré-requisitos temporais associados a esses tipos de verbos, que impõem uma localização futurativa às predicações com que se combinam.

Tal como seria de prever, a estrutura ir no Imperfeito + Infinitivo parece ser aquela que melhor se conjuga com as propriedades semânticas de verbos como prometer ou decidir, uma vez que o valor temporal de posterioridade no passado é o seu traço distintivo mais relevante. Os exemplos que se seguem confirmam essa ideia:

(73) O ministro prometeu que ia falar com os jornalistas. $(e 1<e 2)$

(74) Os bombeiros decidiram que iam abandonar o local. $(e 1<e 2)$

(75) A Joana prometeu que ia ser médica. $(e 1<e 2)$

(76) A Maria decidiu que ia estar grávida. $(e 1<e 2)$

Em configurações como essas, parece existir uma plena compatibilidade entre os pré-requisitos impostos pelo verbo matriz e as propriedades semânticas básicas que caracterizam a estrutura ir no Imperfeito + Infinitivo, na medida em que ambos convergem para uma interpretação de posterioridade num domínio temporal passado.

Dados como os discutidos na presente subsecção deste trabalho sustentam a ideia de que, apesar de se mostrar muito relevante, não é unicamente a contribuição dos tempos gramaticais que determina as relações temporais na computação final das orações completivas. Nesse caso concreto, o papel desempenhado pelo verbo introdutor é de inegável importância e revela-se muitas vezes fundamental para o licenciamento e para a interpretação das configurações em apreço.

\subsection{Verbos factivos: constatar e descobrir}

Verbos introdutores do gênero de constatar ou de descobrir manifestam a propriedade de requererem a veracidade da situação 
com que se combinam no mundo real, i.e., possibilitam assumir que as proposições no seu escopo são verdadeiras em $w 0$, o mundo de referência.

Embora se mostrem perfeitamente compatíveis com todas as possibilidades de ordenação temporal que se possam estabelecer entre os intervalos relevantes, verbos factivos como constatar ou descobrir favorecem tipicamente relações de anterioridade ou de sobreposição da situação subordinada face ao tempo do verbo introdutor, na medida em que, desse modo, a atualização da eventualidade em questão no mundo de referência se encontra, à partida, assegurada. A projeção de situações para o futuro só parece ser admissível se existir forte evidência de que elas terão efetivamente lugar no mundo real.

Dadas as observações que acabamos de explicitar, colocaremos aqui a hipótese de que, com verbos factivos do gênero de constatar ou de descobrir, as leituras futurativas se revelam as menos representativas, sendo evitadas sempre que possível. Vejamos se uma tal predição se confirma no que se refere à interpretação dos tempos gramaticais que analisamos ao longo do presente trabalho.

Começando pelo Imperfeito, verificamos que, no contexto de predicações estativas, prevalece uma leitura de sobreposição no passado, como os exemplos seguintes nos confirmam:

(77) O professor constatou que os alunos eram barulhentos. $(e 1$ o $e 2)$

(78) Os jornalistas descobriram que o ministro estava no hotel. (e1 o $e 2)$

Quando, na subordinada, estão envolvidos eventos, o Imperfeito continua, ainda assim, a favorecer uma leitura de sobreposição no passado. Nessas circunstâncias, ou são conferidas interpretações semiprogressivas (cf. (79)-(80), ou são viabilizadas leituras habituais (cf. (81)-(82) para as predicações em questão.

(79) A Maria constatou que chovia (= estava a chover). (el o e2)

(80) A polícia descobriu que os bandidos assaltavam (= estavam a assaltar) o banco. (e1 o e2)

(81) Os pastores constataram que os lobos lhes comiam as ovelhas (sempre que entravam na aldeia). ( $e 1$ o $e 2)$ 
(82) A polícia descobriu que os bandidos traficavam droga (habitualmente). (e1 o e2)

Tanto nos casos em que o Imperfeito exprime semiprogressividade quanto naqueles em que expressa quantificação sobre situações ou habitualidade, a sobreposição da eventualidade na subordinada relativamente ao PPT conferido pela frase matriz parece ser a única conexão temporal viabilizada (e.g. em (80) a descoberta por parte da polícia é perspectivada como sendo simultânea com respeito ao assalto e, em (82), encontramo-nos perante um caso em que a sobreposição resulta do estabelecimento de uma relação de inclusão: em particular, a situação de "os bandidos traficarem droga" parece incluir o momento da descoberta).

As interpretações futurativas do Imperfeito com verbos como constatar ou descobrir revelam-se normalmente bastante problemáticas, mesmo quando estão envolvidos adverbiais orientados para o futuro. Assim, e ao contrário do que normalmente sucede com os verbos dicendi descritos em 3.1, os verbos factivos manifestam alguma dificuldade em combinar-se com subordinadas no Imperfeito que contenham expressões que inequivocamente remetam para a posterioridade, tal como os exemplos que se seguem nos confirmam:

(83) ?? A Maria constatou que chovia amanhã / daí a dois dias.

(84) ?? A polícia descobriu que os bandidos traficavam droga amanhã / daí a dois dias. ${ }^{27}$

No que diz respeito ao Condicional, a sua interpretação puramente temporal de posterioridade em relação a um PPT passado revela-se - pelo menos para alguns falantes do $\mathrm{PE}$ - igualmente problemática no contexto de verbos factivos como constatar ou descobrir, independentemente da classe aspectual das predicações envolvidas:

\footnotetext{
${ }^{27}$ Sublinhe-se, no entanto, que, mesmo no contexto de verbos factivos como constatar e descobrir, uma interpretação futurativa do Imperfeito, quando acompanhado de adverbiais temporais que expressam posterioridade, é, por vezes, perfeitamente aceitável, sobretudo se o contexto mostra inequivocamente a veracidade da subordinada no mundo de referência, como ilustrado em (i): A Maria constatou que a nova loja abria amanhã / daí a dois dias. $(e 1<e 2)$
} 
?? A Maria constatou que choveria.

(86) ?? O Pedro descobriu que o vizinho compraria uma casa nova.

(87) ?? A Rita constatou que estaria grávida.

(88) ?? Os policiais descobriram que o assaltante seria japonês. ${ }^{28}$

Todavia, as subordinadas envolvendo o Condicional no contexto de verbos factivos melhoram significativamente se, para além do seu valor temporal, essa forma verbal manifestar concomitantemente algum tipo de modalidade associada, particularmente se for introduzida uma oração condicional, como ilustrado nos seguintes exemplos:

(89) O polícia constatou que os bandidos fugiriam da cadeia se a vigilância não fosse reforçada.

(90) O Pedro descobriu que o vizinho compraria uma casa nova se ganhasse a lotaria.

Se, nesses casos, a veracidade da proposição na subordinada não está assegurada em $w 0$, como seria de esperar no contexto de verbos factivos, ela parece, no entanto, ser encarada como uma inevitabilidade logo que as condições descritas na prótase da condicional se encontrem plenamente satisfeitas, o que parece ser suficiente para o licenciamento deste tipo de configurações.

${ }^{28}$ É curioso observar que, para alguns falantes, frases como essas se revelam perfeitamente aceitáveis. Por exemplo, um revisor anônimo deste trabalho afirma que não encontra qualquer dificuldade em interpretar as configurações em (85)-(88) como casos de posterioridade da situação na subordinada face ao tempo estabelecido pela matriz. As oscilações de interpretabilidade observadas no que diz respeito a esse gênero de estruturas poderão constituir um argumento interessante em favor da ideia de que o Condicional se constitui, de fato, como um caso de fronteira entre a temporalidade e a modalidade. Para os falantes que aceitam frases como (83)-(88) com valor de posterioridade, o que parece preponderar é o valor temporal de "futuro do passado" associado ao Condicional; para os falantes que as consideram algo anômalas, pelo contrário, o Condicional estará mostrando a perda acentuada das suas propriedades temporais, o que teria como consequência a prevalência das características lexicais do verbo matriz sobre a sua capacidade de induzir leituras futurativas. 
Outros usos modais do Condicional no contexto sob análise parecem ser mais problemáticos. É o que sucede com o Condicional com valor evidencial ou potencial, na medida em que, exprimindo um certo grau de incerteza, parece entrar em contradição ou em conflito com os prérequisitos que lexicalmente caracterizam os verbos factivos (cf. (91)-(92)):

(91) \# A mãe constatou que a Maria estaria grávida. (e1 o e2)

(92) \# Os jornalistas descobriram que o ministro estaria no gabinete. $(e 1$ o $e 2)$

Finalmente, será interessante referir que, em circunstâncias adequadas, o Condicional em proposições subcategorizadas por verbos como constatar ou descobrir pode receber uma interpretação que exprime a designada modalidade disposicional ou de capacidade (cf. e.g. PORTNER, 2009). Considerem-se os seguintes exemplos:

(93) O professor constatou que a Maria seria uma excelente cantora.

(94) O treinador descobriu que o Tiago jogaria tênis.

Nas suas interpretações mais naturais, frases como essas, embora não assegurem, de forma direta, a veracidade das proposições envolvidas nas respectivas subordinadas, validam em $w 0$ as condições necessárias e suficientes para que tal possa vir a suceder no futuro. Por outras palavras, em (93), por exemplo, o professor verifica que, no mundo de referência, a Maria tem reunidas todas as capacidades, características e disposições para que, num intervalo posterior ao PPT relevante, venha a ser uma excelente cantora.

Em síntese, diremos que o Condicional, quando combinado com verbos factivos do tipo de constatar ou de descobrir, veicula preferencialmente valores de natureza modal que, no entanto, terão de ser, de alguma forma, compatíveis com os requisitos de veracidade associados aos verbos introdutores com que coocorre.

Observe-se, finalmente, o comportamento da estrutura ir no Imperfeito + Infinitivo no contexto de verbos factivos. Tendo em conta que essa forma expressa essencialmente posterioridade no passado, decorrendo os valores modais que por vezes manifesta do seu perfil temporal básico, não surpreende que se revele capaz de estabelecer, 
também nesses casos, uma relação de futuridade face ao PPT fornecido pelo verbo matriz, estejam envolvidas predicações de natureza eventiva ou estativa:

(95) Os jornalistas constataram que o ministro ia discursar. $(e 1<e 2)$

(96) A polícia descobriu que os bandidos iam assaltar o banco. $(e 1<e 2)$

(97) O Rui constatou que o vizinho ia viver em Paris. $(e 1<e 2)$

(98) Os jornalistas descobriram que o ministro ia estar no hotel. $(e 1<e 2)$

Naturalmente, tendo em conta que frases como essas descrevem situações projetadas para o futuro, não será possível, à partida, garantir a veracidade da sua realização no mundo de referência. No entanto, o valor factivo associado a verbos como constatar ou descobrir faz supor que uma interpretação verídica para essas proposições é a preferencial, pelo menos na perspectiva dos sujeitos da oração matriz, i.e., o uso dos verbos em questão implica a consideração de fortes indícios conducentes à realização das eventualidades em $w 0$.

Assim, em (96), por exemplo, mesmo que os bandidos nunca cheguem a assaltar efetivamente o banco em $w 0$, essa situação é encarada como o resultado previsível dado o decurso normal dos acontecimentos no momento de avaliação, ou seja, é concebida como o inertia future preferencial no contexto em questão (cf. DOWTY, 1979).

Em síntese, diremos que verbos factivos do gênero de constatar ou de descobrir, na medida em que favorecem uma leitura verídica das situações nas subordinadas com que se combinam, evitam interpretações em que a veracidade dessas eventualidades possa ser posta em causa. Nessa medida, com o Imperfeito, estabelecem leituras de sobreposição no passado, em que, tipicamente, a verdade das situações se encontra desde logo assegurada; com o Condicional, por seu lado, selecionam os usos modais que, de alguma forma, se mostrem mais compatíveis com a realização das proposições em $w 0$ e, finalmente, com a construção ir no Imperfeito + Infinitivo, admitem interpretações temporais de posterioridade no passado, que, no entanto, se devem constituir como inertia futures preferenciais. 


\subsection{Verbos intensionais: sonhar, imaginar e acreditar}

Um último grupo de verbos introdutores de completivas que analisaremos no presente trabalho é constituído pelos designados verbos ficcionais (fiction verbs; cf. FARKAS, 1992, 2003), como sonhar ou imaginar, e por verbos de atitude proposicional não factivos, como acreditar (cf. HEIM, 1992; FARKAS, 2003). Em comum, essas formas revelam a característica de veicular, em certa medida, algum tipo de intensionalidade, i.e., trata-se de verbos que favorecem leituras não verídicas das proposições representadas no seu escopo. Nesse sentido, vamos designá-los aqui, ainda que de um modo um pouco informal, como verbos intensionais.

A principal questão que aqui nos vai ocupar é a de saber se o fato de as proposições encaixadas não poderem ser tipicamente encaradas como verdadeiras no mundo de referência influencia, de algum modo, as relações temporais que se estabelecem entre principal e subordinada no contexto deste gênero de completivas.

No que toca ao uso do Imperfeito, observamos que uma relação de sobreposição no passado parece ser preferencial, não só quando estão envolvidas predicações estativas (cf. (99)-(100)), mas também quando ocorrem eventos (cf. (101)-(102)):

(99) O João imaginou que tinha um cavalo branco. (e1 o e2)

(100) A Rita acreditou que estava grávida. ( 1 l o e2)

(101) A Maria sonhou que corria pela floresta. (e1 o e2)

(102) O Rui imaginou que pilotava um avião. $(e 1 \text { o } e 2)^{29}$

\footnotetext{
${ }^{29}$ A relação de sobreposição no passado ostentada pelos eventos em frases como (101) ou (102) sugere que, mais uma vez, o Imperfeito atua aqui como um verdadeiro estativizador, nomeadamente dando origem a leituras de tipo semiprogressivo. No entanto, em contextos favoráveis, podemos encontrar Imperfeitos com leituras quantificacionais / habituais (cf. (i)) ou mesmo disposicionais (cf. (ii)), mantendo-se sempre, porém, inalterada a relação preferencial de sobreposição no passado:

(i) O Cristiano sonhou que jogava futebol todos os dias. ( $e 1$ o $e 2)$

(ii) A Maria acreditou que cantava ópera (= era capaz de cantar ópera). $(e 1$ o $e 2)$
} 
Embora, em termos gerais, as proposições da subordinada não sejam verdadeiras no mundo de referência, revelam-se, não obstante, cotemporais em relação às situações descritas na oração principal, sendo avaliadas, nesses contextos, não relativamente ao mundo real, mas a um mundo possível alternativo a $w 0$.

Se procedermos à introdução de adverbiais temporais orientados para o futuro na oração subordinada, observamos que, com predicações estativas, o resultado é, quase sempre, anomalia semântica, o que indicia que, com essa classe aspectual, a leitura de sobreposição no passado, no contexto de verbos intensionais, é praticamente obrigatória.

(103) * O João sonhou que era alto amanhã / daí a dois dias.

(104) * A Maria acreditou que gostava de linguística amanhã / daí a dois dias.

Os eventos, por sua vez, manifestam uma maior variabilidade de comportamentos: em alguns casos, as leituras futurativas do Imperfeito parecem perfeitamente aceitáveis (cf. (105)-(106)), ao passo que, noutros, a sua admissibilidade suscita algumas dúvidas (cf. (107)-(108)):

(105) O João imaginou que comprava um BMW amanhã / daí a dois dias. $(e 1<e 2)$

(106) O jornalista acreditou que entrevistava o presidente amanhã / daí a dois dias. $(e 1<e 2)$

(107) ?? A Maria sonhou que passeava no jardim amanhã / daí a dois dias.

(108) ?? O jornalista acreditou que escrevia um artigo amanhã / daí a dois dias.

A ocorrência de formas do Condicional nas subordinadas de completivas introduzidas por verbos como sonhar, imaginar ou acreditar dá origem a um conjunto bastante diversificado de interpretações.

Em primeiro lugar, podemos obter leituras futurativas, em que o Condicional localiza uma situação num intervalo subsequente ao Ponto de Perspectiva Temporal passado fornecido pelo verbo matriz, tal como ilustrado nos exemplos que se seguem: 
(109) O Rui acreditou que estaria no Brasil no próximo ano. $(e 1<e 2)$

(110) O João imaginou que encontraria um poço de petróleo no seu quintal. $(e 1<e 2)$

É, no entanto, importante sublinhar que essas leituras eminentemente temporais do Condicional são frequentemente acompanhadas por certas aceções com valor modal, particularmente relacionadas com a expressão da vontade, do desejo ou da predição.

Uma segunda interpretação que poderá ser conferida ao Condicional nesse gênero de contextos tem relação com a expressão de uma proposição hipotética decorrente da introdução de uma oração condicional na estrutura, possibilidade que, como já vimos, é partilhada por outros tipos de completivas (cf. (111)-(112)).

(111) O Rui imaginou que voaria se tivesse asas.

(112) O candidato acreditou que seria eleito presidente se passasse à segunda volta das eleições.

Uma outra interpretação do Condicional que emerge frequentemente nesse tipo de contextos, sobretudo quando o verbo matriz selecionado é acreditar, tem a ver com a denotação de capacidades ou de disposições gerais associadas às entidades envolvidas (cf. PORTNER, 2009)). Nessa medida, em frases como as que se seguem, o Condicional manifesta essencialmente um valor modal que se traduz na atribuição, num intervalo futuro, de capacidades específicas ao sujeito da subordinada.

(113) O Cristiano acreditou que jogaria futebol (= seria jogador de futebol).

(114) O professor de desenho acreditou que a Ana pintaria belos quadros (= teria, no futuro, a capacidade de pintar belos quadros).

As proposições "jogar futebol", em (113), e "pintar belos quadros", em (114), não são aqui preferencialmente interpretadas como eventos singulares localizados num intervalo posterior ao PPT relevante, 
mas antes como afirmações de âmbito geral acerca das capacidades ou das disposições futuras das entidades envolvidas, tal como as paráfrases apresentadas deixam bem claro.

Finalmente, o Condicional pode, em circunstâncias adequadas, favorecer uma relação de sobreposição no passado entre a subordinada e a matriz no contexto de completivas introduzidas por verbos intensionais. É o que constatamos nos exemplos que se seguem:

(115) O Rui imaginou que a Rita viveria em Paris (nessa altura / nesse momento). (el o e2)

(116) Os pastores acreditaram que os lobos estariam na aldeia (e por isso fecharam os seus rebanhos no redil). $(e 1$ o $e 2)$

Em exemplos como os que acabamos de apresentar, a relação de cotemporalidade entre as eventualidades representadas na matriz e na subordinada parece perfeitamente natural, o que pode ser comprovado pela compatibilidade com adverbiais temporais do gênero de "nessa altura" ou de "nesse momento" com uma leitura anafórica (cf. (115)). Estaremos, pois, perante casos de um Condicional de probabilidade (cf. MARTÍNEZ-ATIENZA, 2012) ou de conjetura (cf. VATRICAN, 2014), tal como discutido na seção 2.2.

Com efeito, nas suas leituras mais naturais, frases como (115) e (116) parecem expressar situações que possivelmente estão a decorrer no intervalo fornecido pelo PPT mas cujo valor de verdade não foi ainda assegurado (e.g. é possível que a Rita esteja a viver em Paris no intervalo de tempo em que o Rui o imagina ou é possível que os lobos estejam na aldeia no período de tempo em que decorre a crença dos pastores, mas essas proposições não são perspectivadas como verdadeiras ou devidamente confirmadas em $w 0$ ). Sob esse ponto de vista, portanto, o Condicional veicula, em exemplos como os apresentados anteriormente, um valor estritamente modal, funcionando como uma espécie de operador epistémico de possibilidade.

Quanto à estrutura ir no Imperfeito + Infinitivo, quando surge em subordinadas de completivas introduzidas por verbos como sonhar, imaginar ou acreditar, parece veicular preferencialmente informação temporal de posterioridade em relação ao PPT passado fornecido pelo verbo matriz, independentemente de estarem em causa estados ou eventos, como ilustrado nos exemplos que se seguem: 
(117) O Rui imaginou que ia viver em Paris. $(e 1<e 2)$

(118) Os jornalistas acreditaram que o ministro ia estar no hotel (daí a duas horas). (e1<e2)

(119) A Maria sonhou que ia partir de férias. $(e 1<e 2)$

(120) Os policiais acreditaram que iam prender o assaltante. $(e 1<e 2)$

Tendo em consideração que a estrutura ir no Imperfeito + Infinitivo expressa consistentemente uma relação temporal de posterioridade no passado, não surpreende que a ocorrência de leituras potenciais ou conjeturais, perfeitamente naturais com o Condicional, seja, no contexto em apreço, praticamente impossível, na medida em que, como já referimos anteriormente, supõe a sobreposição entre os intervalos em que decorrem as situações descritas.

(121) Os jornalistas acreditaram que o ministro ia estar no hotel (* nessa altura / * nesse momento $).{ }^{30}(e 1<e 2)$

O fato de a estrutura ir no Imperfeito + Infinitivo não poder comparecer em configurações que expressem conjetura ou evidencialidade não significa, no entanto, que, com verbos como sonhar, imaginar ou acreditar, não possa, igualmente, veicular valores de cariz modal. Na realidade, desde que a condição de posterioridade em relação ao PPT passado seja satisfeita, são viabilizadas diversas interpretações, incluindo casos de contrafactualidade como os ilustrados nos exemplos que se seguem:

(122) A Maria imaginou que ia ser médica, mas acabou por estudar direito.

(123) Os polícias acreditaram que iam prender o assaltante, mas ele escapou.

\footnotetext{
${ }^{30}$ No que se refere a esse gênero de exemplos, os casos de anomalia semântica limitam-se unicamente a estruturas em que se verifica cotemporalidade, i.e., à interpretação em que os adverbiais "nessa altura" ou "nesse momento" estabelecem uma relação anafórica de retomada do tempo fornecido pela eventualidade na frase matriz; quaisquer outras leituras possíveis desses adverbiais serão irrelevantes para a discussão que aqui nos ocupa.
} 
Em suma: dado que verbos intensionais como sonhar, imaginar ou acreditar projetam tipicamente as proposições das subordinadas com que coocorrem num mundo possível diferente do mundo de referência, eles favorecem leituras modais das predicações no seu escopo. Em termos estritamente temporais, esses verbos comportam-se de forma bastante "neutra": o Imperfeito surge tendencialmente em estruturas de sobreposição ao PPT passado disponibilizado pela frase matriz, embora, sob certas condições, compareça igualmente em configurações futurativas, ao passo que o Condicional e a estrutura ir no Imperfeito + Infinitivo dão lugar a posterioridade no passado. Sublinhe-se, no entanto, que o Condicional está envolvido maioritariamente em interpretações de cariz modal, sejam elas de desejo, de possibilidade, de hipótese, de conjetura, de potencialidade ou mesmo de expressão de capacidades ou disposições gerais, leituras que, em muitas ocasiões, se sobrepõem à componente temporal que caracteriza a forma verbal em causa, o que se traduz, por exemplo, em casos evidentes de sobreposição entre as situações envolvidas. A construção ir no Imperfeito + Infinitivo, por seu lado, conquanto sempre sujeita à restrição temporal de futuridade, não deixa de veicular informação modal, particularmente no que se refere à expressão da contrafactualidade.

\section{Conclusões}

Foi possível observar, ao longo do presente artigo, que a expressão da futuridade no passado em PE, no contexto de completivas de verbo, depende de um vasto conjunto de fatores que interagem dinamicamente entre si.

Nessa medida, podemos destacar (i) a influência do verbo matriz - como tivemos oportunidade de constatar, certos verbos do gênero de prometer ou de decidir requerem obrigatoriamente a posterioridade da situação com que se combinam; (ii) o papel de dados adverbiais temporais orientados para o futuro ou de expressões equivalentes - no caso do Imperfeito, a presença de elementos desse tipo pode ser mesmo decisiva para a obtenção de leituras de cariz futurativo; (iii) o perfil aspectual das eventualidades representadas na oração subordinada - com o Imperfeito, as interpretações futurativas são tendencialmente obtidas quando estão envolvidos eventos, mas rejeitadas logo que surgem estativos; com o Condicional, as leituras modais de sobreposição no 
passado ocorrem preferencialmente com estados, mas não com eventos; (iv) a natureza dos tempos gramaticais selecionados - apenas a estrutura ir no Imperfeito + Infinitivo veicula clara e consistentemente uma relação de posterioridade no passado, ao passo que o Condicional possibilita, em determinados contextos modais, a sobreposição entre as situações, e o Imperfeito é visivelmente um tempo que favorece a simultaneidade entre as eventualidades descritas, estando as suas leituras futurativas sujeitas a diversas restrições de caráter semântico.

\section{Agradecimentos}

Agradeço à Fundação para a Ciência e a Tecnologia de Portugal, pelo apoio financeiro ao projeto de que este artigo faz parte; os meus agradecimentos estendem-se igualmente ao Centro de Linguística da Universidade do Porto, à equipe editorial e aos revisores anônimos da RELIN, bem como ao grupo de semântica do CLUP, pelas discussões e sugestões que tanto contribuíram para a versão final deste trabalho.

Trabalho financiado pela Fundação para a Ciência e a Tecnologia no âmbito do QREN - POPH (Programa Operacional Potencial Humano) Tipologia 4.1 - Formação Avançada, comparticipado pelo Fundo Social Europeu e por fundos nacionais do MEC

\section{Referências}

ABOUDA, L. Les emplois journalistique, polémique, et atténuatif du conditionnel. Un traitement unitaire. In: DENDALE, P.; TASMOWSKI, L. (Ed.). Le conditionnel en français. Metz: Université de Metz, 2001. p. 277-294.

ANAND, P.; HACQUARD, V. The role of the imperfect in Romance counterfactuals. In: SINN UND BEDEUTUNG, 14., 2009. Wien. Proceedings... Wien: Universität Wien, 2009. p. 37-50.

ARCHE, M. J. The construction of viewpoint aspect: the imperfective revisited. Natural Language \& Linguistic Theory, Springer Link, v. 32, n. 3, p. 791-831, 2014.

ARREGUI, A. M.; RIVERO, L.; SALANOVA, A. Cross-linguistic variation in imperfectivity. Natural Language \& Linguistic Theory, Springer Link, v. 32, n. 2, p. 307-362, 2014. 
BERTINETTO, P. M.; LENCI, A. Pluractionality, habituality and gnomic imperfectivity. In: BINNICK, R. (Ed.). Oxford Handbook of Tense and Aspect. Oxford: Oxford University Press, 2012. p. 852-880.

BERTHONNEAU, A.-M.; KLEIBER, G. Pour une nouvelle approche de l'imparfait: l'imparfait, un temps anaphorique méronomique. Langages, Persée, v. 27, n. 112, p. 55-73, 1993. Doi: https://doi.org/10.3406/ lgge.1993.1661.

BURGOS, J. M. Estatividad y aspecto gramatical. 2013.428f. Dissertação (Doutorado) - Universität Regensburg, Regensburg, 2013.

CHIERCHIA, G. Individual-level predicates as inherent generics. In: CARLSON, G.; PELLETIER, F. J. (Ed.). The Generic Book. Chicago: the University of Chicago Press, 1995. p. 176-223.

CIPRIA, A.; ROBERTS, C. Spanish imperfecto and pretérito: truth conditions and aktionsart effects in a Situation Semantics. Natural Language Semantics, Springer Link, v. 8, n. 4, p. 297-347, 2000.

CUNHA, C.; CINTRA, L. Nova gramática do português contemporâneo. Lisboa: Edições Sá da Costa, 1984.

CUNHA, L. F. As construções com progressivo no português: uma abordagem semântica. 1998. 168f. Dissertação (Mestrado) - Faculdade de Letras da Universidade do Porto, Porto, 1998.

CUNHA, L. F. Semântica das predicações estativas: para uma caracterização aspectual dos estados. 2004. Tese (Doutorado) - Faculdade de Letras da Universidade do Porto, 2004. [Publicada Munique: Lincom Europa GmbH, 2007.]

CUNHA, L. F. Iteração, frequência e habitualidadde: algumas reflexões. In: CONGRÉS DE LINGÜÍSTICA GENERAL, VII., 2006. Actas... Barcelona: Departament de Lingüística General, Universidade de Barcelona, 2006. Disponível em CD-Rom. In: SILVANO, P.; LEAL, A. (Coord.). Estudos de Semântica. Porto: Faculdade de Letras da Universidade do Porto / Centro de Linguística da Universidade do Porto, 2015. p. 211-231.

CUNHA, L. F. Algumas considerações em torno das interpretações da construção ir + Infinitivo com Imperfeito. Diacrítica - Revista do Centro de Estudos Humanísticos da Universidade do Minho, Série Ciências da Linguagem, Braga, v. 29, n. 1, p. 147-170, 2015. 
CUNHA, L. F.; SILVANO, P. A interpretação temporal dos Infinitivos em orações completivas de verbo. In: OLIVEIRA, F.; BARBOSA, J. (Org.). Textos Selecionados do XXI Encontro Nacional da Associação Portuguesa de Linguística. Lisboa: Colibri, 2006. p. 303-314.

DE SWART, H. Aspect shift and coercion. Natural Language and Linguistic Theory, Springer Link, v. 16, n. 2, p. 347-385, 1998.

DECLERCK, R. Tense in English: its structure and use in discourse. Londres; Nova York: Routledge, 1991.

DECLERCK, R. The grammar of the English tense system. Berlim: Mouton de Gruyter, 2006.

DELFITTO, D.; BERTINETTO, P. M. A case study in the interaction of aspect and actionality: the Imperfect in Italian. In: BERTINETTO, P.M.; BIANCHI, V.; HIGGINBOTHAM, J.; SQUARTINI, M. (Ed.). Temporal reference, aspect and actionality. Torino: Rosenberg \& Sellier, 1995. v. 1, p. 125-142.

DENDALE, P. Les problèmes linguistiques du conditionnel français. In: DENDALE, P.; L. TASMOWSKI, L. (Ed.). Le conditionnel en français. Metz: Université de Metz, 2001. p. 7-18.

DENDALE, P. Conditionnel, corrélation, incertitude. Quelques réflexions. In: NORÉN, C.; JONASSON, K.; NOLKE, H.; SVENSSON, M. (Ed.). Modalité, évidentialité et autres friandises langagières. Mélanges offerts à Hans Kronning à l'occasion de ses soixante ans. Berna: Peter Lang, 2013. p. 61-79.

DOWTY, D. Word meaning and Montague grammar. Dordrecht: Reidel Publishing Company, 1979. Doi: https://doi.org/10.1007/978-94-0099473-7.

FARKAS, D. On the semantics of subjunctive complements. In: HIRSCHBÜHLER, P.; KOERNER, K. (Ed.). Romance Languages and Modern Linguistic Theory. Amsterdam: John Benjamins, 1992. p. 69-105. Doi: https://doi.org/10.1075/cilt.91.07far.

FARKAS, D. Assertion, belief and mood choice. In: ESSLLI CONDITIONALAND UNCONDITIONAL MODALITY WORKSHOP, 2003. Viena. Disponível em: <https://people.ucsc.edu/ farkas/papers/ mood.pdf $>$. Acesso em: 2 jul. 2017. Comunicação apresentada. 
FERREIRA, I. O Tempo nas construções condicionais. 1996. Dissertação (Mestrado) - Faculdade de Letras da Universidade do Porto, Porto, 1996.

FERREIRA, M. Imperfectives and plurality. In: SEMANTICS AND LINGUISTIC THEORY, XIV., 2004. Ithaca. Proceedings... New York: Cornell University Press, 2004. p. 74-91. Doi: https://doi.org/10.3765/ salt.v14i0.2915.

GIORGI, A.; PIANESI, F. Tense and Aspect: from semantics to morphosyntax. Oxford; Nova York: Oxford University Press, 1997.

HEIM, I. Presupposition projection and the semantics of attitude verbs. Journal of Semantics, Oxford Academic, v. 9, n. 3, p. 183-221, 1992. Doi: https://doi.org/10.1093/jos/9.3.183.

IPPOLITO, M. Imperfect modality. In: GUÉRON, J.; LECARME, J. (Ed.). The syntax of time. Cambridge, MA: MIT Press, 2004. p. 359-387.

KAMP, H.; ROHRER, C. Tense in texts. In: BAUERLE, R.; SCHWARZE, C.; VON STECHOW, A. (Ed.). Meaning, use and interpretation of language. Berlim: Walter de Gruyter, 1983. p. 250-269. Doi: https://doi. org/10.1515/9783110852820.250.

KAMP, H.; ROHRER, C.; REYLE, U. From discourse to logic. Introduction to model-theoretic semantics of natural language, formal logic and discourse representation theory. Dordrecht: Kluwer Academic Publishers, 1993.

KLEIN, W. Time in language. Londres: Routledge, 1994.

LENCI, A. The semantic representation of non-quantificational habituals. In: BERTINETTO, P. M.; BIANCHI, V.; HIGGINBOTHAM, J.; SQUARTINI, M. (Ed.). Temporal reference, aspect and actionality: semantic and syntactic perspectives. Torino: Rosenberg \& Sellier, 1995. V. 1, p. 143-158.

LENCI, A.; BERTINETTO, P. M. Aspects, adverbs, and events: habituality vs. perfectivity. In: HIGGINBOTHAM, J.; PIANESI, F.; VARZI, A. C. (Ed.). Speaking of events. Nova York; Oxford: Oxford University Press, 2000. p. 245-287.

MARTÍN, A. B. La perífrasis “ir a + Infinitivo” en el sistema temporal y aspectual del Español. 2008. Dissertação (Doutorado) - Universidad Complutense de Madrid, Madrid, 2008. 
MARTÍNEZ-ATIENZA, M. Formas verbales en contraste en italiano y en español: similitudes, diferencias y explicación. RAEL: Revista Electrónica de Lingüistica Aplicada, Dialnet, v. 11, p. 69-86, 2012.

MATOS, S. Aspectos da semântica e pragmática do Imperfeito do Indicativo. Revista da Faculdade de Letras: Linguas e Literaturas, Faculdade de Letras da Universidade do Porto, Série II, v. 13, p. 435474, 1996.

MOENS, M. Tense, Aspect and temporal reference. 1987. Tese (Doutorado) - Edinburgh University, Edinburgh, 1987.

MOENS, M; STEEDMAN, M. Temporal ontology and temporal reference. Computational Linguistics, MIT Press, v. 14, p. 15-28, 1988.

OLIVEIRA, F. Algumas considerações acerca do Pretérito Imperfeito. In: ENCONTRO DA ASSOCIAÇÃO PORTUGUESA DE LINGUÍSTICA, 2., 1987. Lisboa. Actas... Lisboa: APL, 1987. p. 78-96.

OLIVEIRA, F. Algumas questões semânticas acerca da sequência de tempos em Português. Revista da Faculdade de Letras: Línguas e Literaturas, Faculdade de Letras da Universidade do Porto, Série II, V. 15, p. 421-436, 1998.

OLIVEIRA, F.; DUARTE, I. M. Le conditionnel et l'imparfait en Portugais Européen. Faits de Langues, Persée, v. 40, n. 2, p. 53-60, 2012.

OLIVEIRA, F.; LOPES, A. C. M. Tense and aspect in Portuguese. In: THIEROFF, R. (Ed.). Tense systems in European languages. Tübingen: Niemeyer, 1995. v. II, p. 95-115. Doi: https://doi. org/10.1515/9783110958911.95.

PERES, J. A. Towards an integrated view of the expression of time in Portuguese. Cadernos de Semântica, Lisboa, Faculdade de Letras da Universidade de Lisboa, n. 14, 1993.

PORTNER, P. Modality. Oxford: Oxford University Press, 2009.

RODRIGUES, A. B. Traços de tempo e aspecto e subespecificação morfológica do auxiliar «ir» em construções no futuro do presente e no futuro do pretérito. Revista Brasileira Linguística Aplicada, Belo Horizonte, v. 19, n. 2, p. 215-239, 2011. Doi: https://doi. org/10.17851/2237-2083.19.2.215-239. 
SILVA, A. A expressão da futuridade na língua falada. 1997. Tese (Doutorado) - Universidade Estadual de Campinas, Instituto de Estudos da Linguagem, Campinas, 1997.

SILVANO, P. Sobre a semântica da sequência de tempos em Português Europeu. Análise das relações temporais em frases complexas com completivas. 2002. Dissertação (Mestrado) - Universidade do Minho, Braga, 2002.

SQUARTINI, M. The internal structure of evidentiality in Romance. Studies in Language, John Benjamins, v. 25, n. 2, p. 297-334, 2001. Doi: 10.1075/s1.25.2.05squ

TRAVAGLIA, L. C. O discurso no uso do pretérito imperfeito do indicativo no português. Cadernos de Estudos Lingüisticos, Unicamp, n. 12, p. 61-98, 1987.

VATRICAN, A. El condicional de cortesía en español: la hipótesis como forma de atenuación. In: NEBOT, A. C.; RUIZ, M. J. A.; LÓPEZNAVARRA, E. (Org.). Estudios de lingüística: investigaciones, propuestas y aplicaciones. Valencia: Universitàt de Valencia, 2013. p. 469-480.

VATRICAN, A. Usos y valores modales del condicional en español. Archivum, University of Liverpool, v. 64, p. 239-273, 2014. Disponível em: <http://www.unioviedo.net/reunido/index.php/RFF/article/ view/10319>. Acesso em: 2 jul. 2017. 
